\title{
Polypide anatomy of hornerid bryozoans (Stenolaemata: Cyclostomatida)
}

2 Running title: Polypide anatomy of hornerids

3

4 Yuta Tamberg*, Peter B. Batson, Ruth Napper

6 Department of Marine Science, University of Otago, P.O. Box 56, Dunedin, New Zealand

7 Department of Anatomy, University of Otago, P.O. Box 56, Dunedin, New Zealand

8 * Corresponding author: tel.: +6434795085; e-mail: yutamberg@ gmail.com

9

\section{Abstract}

11 Bryozoans are small colonial coelomates whose colonies are made of individual modules (zooids).

12 Like most coelomate animals, bryozoans have a characteristic body wall composition, including

13 epidermis, extracellular matrix (ECM) and coelothelium, all pressed together. The order

14 Cyclostomatida, however, presents the most striking deviation, in which the ECM and the

15 corresponding coelothelium underlying major parts of the skeletal wall epidermis are "peeled off" to

16 form an independent membranous sac. The polypide anatomy and ultrastructure of this group is best

17 known from one family, the Crisiidae (Articulata). Here we examined four species from the

18 phylogenetically and ecologically contrasting family Horneridae (Cancellata) from New Zealand.

19 Here we provide the first detailed ultrastructural examination of the hornerid polypide, including

20 tentacles, mouth region, digestive system and the funiculus. We were able to trace continuity and

21 transitions of cell and ECM layers throughout the whole polypide. In addition we identified that the

22 funiculus is a lumen-free ECM cord with two associated muscles, disconnected from interzooidal

23 pores. While agreeing with the general cyclostomate body plan, hornerids have some unique traits

24 that make them worthy of additional study.

25

26 Keywords: Bryozoa, Horneridae, lophophore, ultrastructure, coelom

28 Highlights: Hornerids share a general cyclostomate body plan. The frontal tentacle ECM transitions

29 into oral sphincter ECM, the abfrontal lophophore ECM becomes a septum between coelomic

30 compartments, and the funuculus is a solid ECM cord supplied with muscles. 
Tamberg, p. 2

Bryozoans are small colonial benthic invertebrates living in marine and freshwater environments. The phylum contains three classes (Phylactolaemata, Gymnolaemata, Stenolaemata). Bryozoan colonies are made of individual units, or modules, called zooids, linked with colony-wide elements. The feeding zooids comprise an outer skeletal wall (ectocyst), the living layer or layers of tissues attached to and underlying the skeleton (endocyst), and the polypide - the retractable softbody part of the zooid which includes all its organs.

Bryozoans are coelomic animals with two or three compartments in their body cavities, partially confluent or completely separated (Shunatova \& Tamberg, 2019). In Phylactolaemata these compartments include the coeloms of the epistome, lophophore, and trunk, in Gymnolaemata - the lophophore and trunk coeloms, connected by narrow ciliated ducts. In Stenolaemata there is a lophophore coelom and a modified trunk cavity with two portions. Stenolaemate polypides, unlike other bryozoans, are surrounded by a membranous sac, made of a single coelothelial layer and the ECM, and supplied with delicate muscles (Nielsen \& Pedersen, 1979), whereas the epidermal layer is resting against the skeletal wall. Thus, their main body cavity is split into two parts: the exosaccal cavity outside the membranous sac, and the endosaccal cavity (true coelom) inside it (Figure 1).

The coelomic lining of the tentacles, the lophophore and the tentacle sheath is similar in all bryozoan classes, whereas the trunk lining differs across these groups. Phylactolaemata have an unbroken coelothelium, cheilostomates within Gymnolaemata have lost parts of the ECM and peritoneum, and Stenolaemata have ECM and peritoneum detached from the trunk epidermis in the form of the membranous sac.

In stenolaemates the membranous sac is not completely detached from the cystid. In a wide range of studied species, it has been shown to be anchored to the skeleton proximally at the origin points of the polypide retractor muscles and the funiculus; in addition, there may be various polypidecystid attachments in the distal part of the zooid (e.g. Borg, 1926; Boardman and McKinney, 1985; Boardman 1998; Nielsen, 1970; Nielsen and Pedersen, 1979; Schäfer, 1985; Shunatova and Tamberg, 2019; Schwaha et al., 2018). All such structures provide stability to the polypide during protrusion and retraction.

The Cyclostomatida is the only living order in the exclusively marine class Stenolaemata. Our understanding of the anatomy of cyclostomate polypides is mostly based on light-microscopic studies by Borg (1926), Boardman (1983, 1998), Boardman et al. (1992), Schäfer (1985), Nielsen (1970) and 
63 recently Schwaha et al. (2018). Only a few publications have addressed cyclostomate ultrastructure using electron microscopy: Nielsen and Pedersen (1979), Carle and Ruppert (1983), Nielsen and Riisgard (1998), Shunatova \& Nielsen (2002), Nielsen (2013), Temereva and Kosevich (2018) and Shunatova and Tamberg (2019). In addition, some confocal laser scanning microscopic studies have examined nervous and muscular systems of these animals (Schwaha et al., 2018, Temereva \& Kosevich, 2018, Worsaae et al., 2018).

Although all these studies provided major insights into cyclostomate anatomy, they cover a relatively narrow taxonomic range. A single genus, Crisia (suborder Articulata), is the most-studied cyclostomate; six out of nine recent electron microscopic and confocal studies listed above explore Crisia eburnea or Crisia elongata. Variations of Borg's (1926) and Nielsen and Pedersen's (1979) Crisia autozooid schematics remain the standard depiction of generalized cyclostomate anatomy.

Representatives of Tubuliporidae, Lichenoporidae and Cinctiporidae are much less studied, and other families remain virtually unexplored at the ultrastructural level.

The cancellate cyclostomates in the family Horneridae differ in several key respects from Crisia. The latter is a delicate, ephemeral, subtidal cyclostomate, whereas hornerids are heavily calcified, long-lived, and typically occur in oceanic environments at shelf depths and deeper. Recent molecular phylogeny has confirmed that the Cyclostomatida is monophyletic and that, within this order, hornerids are widely separated from articulates (Waeschenbach et al., 2012). For these reasons, a comparison of hornerids with Crisia can highlight the range of anatomical variation across the Cyclostomatida.

In this paper we explore polypide anatomy and ultrastructure of four hornerid species from southern New Zealand using light and electron microscopic methods. In particular, we trace various epithelial layers of the polypide at the ultrastructural level and compare them to other bryozoans, in order to develop a deeper, more multidimensional understanding of the anatomy of this group. This understanding could lead to improved reconstructions of soft body parts of extinct stenolaemates (see Tamberg \& Smith, 2020). (1)

We examined four hornerid species from two genera: Hornera robusta MacGillivray, 1883, Hornera sp. 1, Hornera sp. 2 and Horneridae gen. sp. 3. The first three species, H. robusta, H. sp. 1 and H. sp. 3 2, were collected annually from 2016 to 2019 from mid-continental shelf off Otago, New Zealand (90 4 m depth, $45^{\circ} 47.89^{\prime} \mathrm{S}, 170^{\circ}$ 54.5' E; see Batson and Probert 2000). Hornera sp. 2 was also sampled in 
952018 near Stewart Island (58 $\mathrm{m}$ and $77 \mathrm{~m} ; 4^{\circ} 54.87^{\prime} \mathrm{S}, 168^{\circ} 13.06^{\prime} \mathrm{E}$ and $47^{\circ} 07.70^{\prime} \mathrm{S}, 1^{\circ} 8^{\circ} 10.79^{\prime} \mathrm{E}$

96 respectively). The last species, Horderidae gen. sp. 3 (planar and curved forms) was obtained in 2016

97 near Snares Islands ( $\left.151 \mathrm{~m} ; 4^{\circ} 43.20^{\prime} \mathrm{S}, 1^{\circ} 7^{\circ} 1.44^{\prime} \mathrm{E}\right)$. Upon collection some colonies were fixed

98 immediately, while others were transported alive to the lab.

99 Living colonies of $H$. robusta and $H$. sp. 2 were kept in flow tanks in an isothermic room at

$100 \sim 13^{\circ} \mathrm{C}$, where they were left to recover from dredging for 3-8 days. Throughout this time the animals

101 were constantly supplied with a mixture of natural particles and cultured algae Rhodomonas salina

102 and Dunaliella tertiolecta using a drip feeder system. Colonies were than examined under the

103 microscope, and fully recovered feeding ones were relaxed with an isotonic solution of magnesium

104 chloride $(\sim 7.5 \%)$ mixed 1:1 with sea water and fixed. Colonies of $H$. sp. 1 and Horneridae gen. sp. 3

105 were fixed immediately upon collection, so that all polypides are in a retracted state.

106 We treated the fixed colonies following three processing pathways: paraffin-embedded

107 material was used for histological examination, epoxy-resin embedded tissue was used for semi-thin

108 sections and TEM, and some material was also specifically processed and embedded in resin for

109 imaging with serial block-face SEM (SBF SEM).

110 For paraffin sections, we fixed the colonies of $H$. robusta with $4 \%$ formalin in sea water,

111 washed, dehydrated through the graded ethanol series and embedded in paraffin (Peterfi method). The

$1125 \mu \mathrm{m}$ thick sections were stained with hematoxylin-eosin.

113 To obtain semi-thin and ultrathin sections, we fixed samples with $2.5 \%$ glutaraldehyde

114 solution in $0.1 \mathrm{M}$ PBS supplemented with sucrose to reach $990 \mathrm{mOsmol}$, and processed using

115 standard TEM protocols. Material was rinsed in 0.1 M PBS with sucrose (990 mOsmol), decalcified

116 with EDTA and transferred into $1 \% \mathrm{OsO}_{4}$ for 1.5 hours. After osmication, the material was washed,

117 dehydrated through a graded ethanol series and pure acetone, and embedded in Embed 812 epoxy

118 resin. Sectioning was done with a diamond knife on Leica EM UC7 ultramicrotome. Resulting series

119 of semi-thin sections ( $1 \mu \mathrm{m}$ thick) were stained with toluidine blue and imaged with a light

120 microscope. Ultrathin sections (80-90 nm) were stained with uranyl acetate and lead citrate and

121 imaged with JEOL JEM 1400 and JEOL 2200FS electron microscopes.

122 Two colonies of $H$. robusta were fixed with glutaraldehyde and processed for SBF SEM

123 (protocol modified from Deerinck et al., 2010). The samples were washed with buffer, pre-treated

124 with $0.1 \%$ tannic acid in buffer for 45 minutes, washed with the same buffer, and post-fixed with

$1251.5 \%$ potassium ferrocyanide and $1 \%$ osmium tetroxide mixture on ice for 1.5 hours. All following

126 washes were done with distilled water. The samples were placed in $1 \%$ thiocarbohydrazide solution 
127 for 30 minutes at $60^{\circ} \mathrm{C}$, and in $2 \% \mathrm{OsO}_{4}$ for 60 minutes. Samples were then stained consecutively

128 with $1 \%$ uranyl acetate overnight and with lead aspartate solution for 30 minutes at $60^{\circ} \mathrm{C}$. Three 5-7

129 minute washes were used between each reagent. After the final wash samples were dehydrated

130 through graded ethanol series and embedded in Durcupan, ACM resin (Electron Microscopy

131 Sciences, USA). SBF SEM sectioning and imaging was done with ZEISS Sigma VP 3View (Sydney

132 University) and Thermo Fisher Apreo with VolumeScope Serial Block Face system (Queensland

133 University) electron microscopes.

134 Electron microscope images are partially represented as negatives converted by ImageMagick

135 6.9. (The ImageMagick Development Team 2021), but not altered otherwise. Tiled montages were

136 aligned with Etomo element of IMOD software (Kremer et al., 1996). All measurements were done

137 from microphotographs using Inkscape 0.92 (Inkscape project 2017).

\section{Results}

140

All hornerid species have tubular zooidal chambers up to $2 \mathrm{~mm}$ long, $60-100 \mu \mathrm{m}$ in internal

142 diameter, narrowing sharply at the proximal end. Regardless of the size and age of the zooid, the

143 polypide invariably occupies the distal-most position, moving 300-500 $\mu \mathrm{m}$ up and down the zooid

144 tube when protruding and retracting. This indicates that both examined genera undergo progressive

145 polypide cycles (sensu Boardman, 1998). There are at least two points where the polypide is attached

146 to the zooid wall: the origin of the retractor muscles $(\sim 450 \mu \mathrm{m}$ from the aperture $)$ and the funiculus

147 (additional $\sim 350 \mu \mathrm{m}$ ). In both Horneridae gen. sp. 3 forms the polypide is additionally anchored to

148 the skeletal wall by distal ligaments.

149 When the polypide is protruded, nine 200-300 $\mu \mathrm{m}$ long tentacles curve outwards in a trumpet-

150 shaped crown. The tentacles protrude from the aperture for $90 \%-100 \%$ of their length. When

151 retracted, tentacles are straightened and arranged in a cylinder.

152 The general anatomy of the studied species is relatively uniform and broadly resembles that

153 described in other Cyclostomatida (Figure 1). In the morphological descriptions, given below, we

154 mostly provide new information or address the points of difference.

155

\subsection{Tentacles}

157 Tentacles are roughly triangular in cross-section, frontal-abfrontal distance is $\sim 17 \mu \mathrm{m}$;

158 maximum lateral width is $\sim 12 \mu \mathrm{m}$ (including cuticle). Organization of the tentacles follows the 
159 standard bryozoan plan: a tube of ECM is surrounded by outer epithelial cells arranged in regular

160 vertical rows, and lined internally with coelothelium. The coelomic cavity is seen as a series of

161 lacunae in both protruded and retracted tentacles.

162 The outer epithelial layer includes: [1] an unpaired midline frontal A-cell, [2] two lateral-

163 frontal B-cells on either side, [3] two frontal-lateral C-cells, [4] two lateral D-cells, [5] two

164 abfrontal-lateral E-cells and (6) an intermittent row of abfrontal F-cells (Figure 2a,b).

165 A-cells are oval in cross-section, elongated $(\sim 8 \mu \mathrm{m})$ along the main tentacle axis, usually with

166 electron-light cytoplasm. In full agreement with previous observations, A-cells never bear cilia. In $H$.

167 robusta the cytoplasm of A-cells often contains numerous vesicles near the apical tip. In Hornera

168 species 1 and 2 the tips of A-cells bear long (1.2-2.2 $\mu \mathrm{m})$ branching microvilli, while in hornerid gen.

169 sp. 3 they are much shorter $(\sim 0.5 \mu \mathrm{m})$.

170 B-cells are of similar size and shape in cross-section, but are much shorter $(\sim 2 \mu \mathrm{m})$ in

171 proximal-distal direction. These are monociliated cells with deeply lobed nuclei and complicated

172 basal complexes including two kinetosomes and four cross-striated rootlets (r1-4 on Figure 2c,d). On

173 each tentacle, lateral-frontal cilia form two closely-spaced rows (Figure 2e). The basal complexes in

174 B-cells on the right and left of the tentacle are mirror-images of each other. The main kinetosome is

175 attached to the apical cell membrane by several short microtubules. In addition, it has one axial cross-

176 striated rootlet (r1) and a basal foot. Both the basal foot and the additional kinetosome are located on

177 the frontal side, i.e., closer to the midline of the tentacle. An additional kinetosome gives off three

178 rootlets: two axial ones ( $\mathrm{r} 2,3)$ and a diagonal one (r4). All axial rootlets (r1, 2, and 3) run close to

179 each other, straight towards the base of the cell, whereas the diagonal rootlet extends in a proximal-

180 basal direction.

181 C-cells cover most of the frontal-lateral surfaces of the tentacles with their elongated flaps

182 pointing forward. They come up nearly to the apical tips of the B-cells but form near-vertical

183 abfrontal borders with the D-cells. In proximal-distal direction C-cells extend for $\sim 5 \mu \mathrm{m}$. C-cells bear

184 numerous long cilia $(\sim 15 \mu \mathrm{m})$ which form the frontal half of the lateral ciliary row (Figure $2 \mathrm{~b})$. Each

185 cilium has a single basal body with a basal foot and two cross-striated rootlets (Figure $2 \mathrm{f}$, cell on the

186 left). The axial rootlet extends basally and abfrontally at a steep angle, whereas a very long lateral

187 rootlet runs underneath the cell membrane in the frontal direction into the cytoplasmic flap. As in

188 other bryozoans, the basal foot always points abfrontally, in the direction of the active ciliary stroke.

189 The microvilli of C-cells are usually short $(\sim 0.2 \mu \mathrm{m})$, except for the area around cilia $(\sim 0.7 \mu \mathrm{m})$. 
190 D-cells are much narrower, almost square in cross-section, shorter in proximal-distal

191 direction. Their frontal side also bears multiple cilia which constitute the second, abfrontal, half of the

192 lateral ciliary row. The basal complex of these cilia includes a single basal body, a basal foot and two

193 rootlets, which are arranged identically to those in C-cells (Figure 2f, cell on the right). The axial

194 rootlet also points basally and abfrontally, while the lateral rootlet runs more sharply downwards and

195 frontally.

196 E-cells never bear cilia. They are somewhat flattened in shape and extend very short

197 cytoplasmic flaps over the abfrontal sides of the adjacent D-cells. Together with intermittent F-cells

198 they cover the entire abfrontal surface of the tentacle. At least some of these cells are ciliated. The

199 ciliary basal complex may include a single kinetosome anchored to the apical cell membrane with

200 short microtubules and bearing a cross-striated axial rootlet which runs diagonally in proximal-basal

201 direction. Sets of two kinetosomes, arranged at right angles, and cupped by a Golgi apparatus, were

202 also found (Figure 2g). Owing to the low frequency of F-cell cilia, we were unable to establish a

203 more detailed model of the basal complex or verify if the basal feet are present or missing.

204 On the apical surface, all cells bear microvilli and cuticle. In all four species microvilli are

205 longest on the frontal surface of the tentacle and near the lateral cilia (Figure 2b). The cuticle is two

206 or three-layered. If present, the top layer is an indistinct felt-like structure composed of fine electron-

207 dense strands attached to the tips of the microvilli. The medial layer comprises a thin horizontal skein

208 of electron-dense strands radiating subterminally from the microvilli tips. The bottom layer is

209 homogeneous and somewhat electron-lucent. The last two layers may be iterated two or more times

210 along the length of the microvilli (Figure 2d,e).

211 Cell contacts are typical for bryozoans and include belt desmosomes in the apical position and

212 septate junctions below (Figure 2f). The basal and lateral cell surfaces do not form interdigitating

213 folds (unlike in phylactolaemate bryozoans).

214 Underneath the outer epithelium we found six basiepithelial nerves: one frontal, two lateral-

215 frontal, two abfrontal-lateral and one abfrontal (Figure $2 \mathrm{~h}$ ).

216 A tube of relatively thick $(\sim 0.3-0.8 \mu \mathrm{m})$ ECM provides axial support to the tentacle. On the

217 inside it is lined by coelothelium and contains a coelom, at times occluded by somata of peritoneal

218 cells. As in other bryozoans, the frontal and abfrontal coelothelial cells are myoepithelial, with

219 contractile portions in contact with the ECM and anchored to it by hemidesmosomes. In some of the

220 tentacles (only $1-2$ per lophophore) we also saw a small muscle running basiepithelialy on the 
221 abfrontal surface of the tentacle (Figure 2b, tinted red). These muscles occurred in all studied species

222 and had no relation to the distance to the tentacle base.

223 Two lateral coelothelial cells lack ciliation or contractile bundles, but in the distal half of the

224 tentacle we often found well-developed secretory apparatus in the form of numerous, long cisternae

225 of rER arranged in loose circles around the nucleus. We were unable to find conclusive proof of the

226 existence of the sub- and epiperitoneal cells on the lateral sides of the tentacle coelom.

\subsection{Lophophore base and the mouth region}

229 The individual tentacles merge at the base of the lophophore (Figures 3, 4): at first the

230 epidermal cells come into contact and the respective tentacle ECMs join more proximally. In both

231 cases the abfrontal-lateral portions merge first, while frontal parts remain distinct for longer (Figure

232 3b). The fate of the frontal and abfrontal structures of the tentacles also differ markedly. The frontal

233 cells transition into the mouth epidermis, and the frontal ECM forms the roof of the ring canal

234 (Figures 3a, 4). The abfrontal cells make the outer lining of the lophophore base, and the abfrontal

235 basement membrane becomes a thick ECM cylinder - the greatest non-skeletal support element of the 236 polypide - and later forms the floor of the ring canal (Figures 3, 4).

237 Above the mouth, the A-, B- and C-cell lines continue onto the preoral region, whereas D-, E-

238 and F-cells appear on the outer surface of the lophophore. As a result, lateral ciliary rows split into

239 frontal and abfrontal portions (Figure 4a). As the C-cells of neighboring tentacles come into contact,

240 the density of ciliary cover decreases and ciliation gradually disappears. Proximally to the last

241 protruding axonemes there are several irregularly arranged naked kinetosomes. Abfrontally, D-cells

242 meet while still bearing cilia, but the ciliation ends quickly. No trace of ciliated pits, described in

243 gymnolaemate bryozoans, was seen, although we observed mitoses at the tentacle bases.

244 The ECM near the tentacle base develops thick abfrontal-lateral horns (up to 10 times thicker

245 than the frontal ECM) which elongate and merge just above the mouth (Figure 4b,c). The basement

246 membranes of the frontal tentacle surfaces retain individuality and continue proximally below the

247 level of the oral sphincter for 5 to $10 \mu \mathrm{m}$ before merging (Figure 4c). After joining together, they

248 abruptly become very delicate and hard to trace even on TEM images. As the tentacle coeloms open

249 up into the ring canal of the lophophore, the unified preoral ECM slopes up towards the oral

250 sphincter, folds over the sphincter muscles and continues downwards as the basement membrane of

251 the pharyngeal epithelium (Figure 4b,d). 
252

253

254 The latter merges with the lophophore ECM slightly below the mouth. The thick outer ECM of the

255 lophophore continues proximally for an additional 10-15 $\mu \mathrm{m}$ (i.e. for $\sim 25 \mu \mathrm{m}$ below the oral

256 sphincter). Large buccal dilator muscles, each of which is an individual cell, cross the ring canal

257 (Figure 4b,e). As they pass between the circular muscles of the oral sphincter, buccal dilators attach

258 to the ECM of the mouth in several places and run radially towards the thick outer ECM. Opposite

259 the buccal dilators, in the endosaccal cavity of the trunk, the outer ECM cylinder also supports the

260 retractor muscles, which attach to its proximal surface around most of the lophophore perimeter

261 (Figures 3b, 4b,c).

262 Below the attachments of the buccal dilators and retractors, the lophophoral ECM abruptly

263 becomes very delicate and slopes down towards the pharynx or around the ganglion (Figure 4b,c).

264 This delicate extracellular layer forms the floor of the ring canal, i.e. the septum separating

265 lophophore and trunk coeloms. The ECM of the septum does not simply merge with the ECM of the

266 pharynx wall. Instead, it forms an outer "leaf" going over the circular muscles of the pharynx (Figure $2674 c)$.

268 The circumoral nerve ring is located in the lophophore coelom, in association with the ECM

269 (Figure 4e). It is, however, impossible to tell exactly how these two structures correspond, since the

270 ECM is so delicate and hard to trace.

271 The ganglion is a relatively small, compact structure sitting between the pharynx and the

272 terminal part of the rectum (Figure 5a). The neuropile forms an invagination in the distal half of the

273 ganglion pointing diagonally towards the mouth (Figure 5b). The distal boundary of the ganglion

274 coincides with the lower parts of the buccal dilators (Figure 5a,c), so that the top of the ganglion is

275 bracketed by two muscle cells. More proximally the ganglion acquires two lateral lobes, similar in

276 appearance to lateral ganglia in Cinctipora elegans (Schwaha et al., 2018). The lobes are compact

277 elongated structures made of cells with electron-dense cytoplasm (Figure 5a). We detected no

278 neuropile and have no immunoreactivity data on these structures, thus we hesitate to call them lateral

279 ganglia.

280 The tentacle sheath is a cylindrical part of the polypide body wall stretching from the origin at

281 the base of the lophophore to the end point where it merges with the vestibular wall and the

282 membranous sac (Figure 6a, white dotted line). In the retracted polypide the tentacle sheath forms the

283 casing around the tentacles, creating a temporary atrial cavity within. When the polypide is protruded, 
284 it forms a flexible stalk that supports the tentacle crown. The location of the point where the tentacle

285 sheath transitions into the membranous sac and the vestibular wall (Figure 6A) is relatively stable

286 regardless of the position of the polypide. It is located approximately 100-150 $\mu \mathrm{m}$ distal of the

287 aperture (which corresponds to the cardia-caecum boundary in a protruded polypide). The origin of

288 the tentacle sheath, which is located at the lophophore base (Figure 6b), moves up and down with the

289 lophophore.

290 The tentacle sheath is a fine structure $\sim 1-2 \mu \mathrm{m}$ thick with squamous coelothelial and epidermal

291 cells resting on a 15-45 $\mathrm{nm}$ ECM. There is no cuticle. Tentacle sheath musculature is represented by

292 very delicate longitudinal muscles (10-15 fibers per cell; Figure 6c). Although the surface is not

293 ciliated, we found a free kinetosome in one of the epidermal cells.

294 The epidermis of the tentacle sheath continues onto the vestibular wall, whereas the

295 coelothelium goes onto the inside of the membranous sac. The ECM material is equally thick in all

296 three structures. More details on the composition of the membranous sac, vestibular wall and terminal

297 membrane will be given in our following publication.

\subsection{Retractor muscles}

$300 \quad$ There are about 50 individual retractor muscle cells in a zooid. They originate from paired

301 semicircular attachment zones on the abanal surface of the zooid wall, about $400 \mu \mathrm{m}$ from the

302 aperture, and connect the polypide to the skeletal wall (Figure 7a,b). In agreement with the protrusion

303 distance of the polypide, the retractor muscles undergo substantial changes in length: from $\sim 50 \mu \mathrm{m}$

304 when contracted to $\sim 370 \mu \mathrm{m}$ when relaxed (Figure $7 \mathrm{a}$ ).

305 The muscles extend proximally towards the basal parts of the lophophore ECM (Figures 4b,

306 7c). In retracted polypides they are arranged in a semicircle cupping the abanal side of the downward

307 branch of the gut, or concentrate in two groups in the space between gut branches. More proximally,

308 retractor muscles spread out to a near-complete circumference, and the lophophore-insertion area

309 encloses most of the lophophore, except for a gap around the ganglion (Figure 5a).

310 Each retractor muscle is an individual cell with unusually shaped nucleus which forms

311 numerous interdigitating protrusions at the interface with the contractile bundles (Figure 7d).

312 Retractor muscles are enclosed within the membranous sac for their entire length. Both at the origin

313 and at the lophophore insertion they are anchored to the ECM with hemidesmosomes (Figure 7c). 
The digestive system of hornerids has a typical bryozoan composition: a downward branch

317 (mouth, pharynx and cardia: Figure 8), a blind sac-like caecum, and an upward branch (pylorus,

318 rectum and anus: Figure 9). The downward branch usually follows the abfrontal surface of the zooid

319 tube and upward branch runs along the frontal surface.

320 The digestive system starts with a round muscular mouth. During normal feeding the mouth is

321 kept open at $\sim 25 \mu \mathrm{m}$ in diameter (it can open even wider for swallowing), while in fixed material it is

322 usually more contracted at $\sim 13 \mu \mathrm{m}$ in diameter. The circular cross-striated muscles around the mouth

323 make up the oral sphincter. Interestingly, the oral sphincter can be identified in living polypides by

324 differential contraction, but has no boundary from the pharyngeal muscles below (Figures $4 b, 5 b$ ).

325 The epithelium of the mouth itself is separated clearly into the upper and lower parts (Figure 5b). The

326 upper part is made of epidermal cells continuous with the frontal cells of the tentacles. They typically

327 have electron-dark cytoplasm and no ciliation. The lower portion of the mouth is lined with

328 occasionally ciliated myoepithelium with distinctly more electron-lucent cytoplasm and an interior

329 composition similar to pharyngeal cells. Thus, the mouth has a more functional than anatomical

330 identity.

331 The pharynx is a direct continuation of the mouth. The outer contours of the pharynx are oval

332 in cross-section, but the lumen is Y-shaped (Figure 8b). The latter form arises from the uneven height

333 of the cells (from $\sim 5 \mu \mathrm{m}$ between ridges to $\sim 15 \mu \mathrm{m}$ on the ridge). All cells are myoepithelial, with the

334 contractile portions arranged vertically, i.e. in apical-basal direction, around the nucleus (Figure 8b).

335 We saw no structural differences in the cells in and between ridges and no indication of anchor cells

336 sensu Nielsen (2013). Their apical surfaces bear long $(\sim 1 \mu \mathrm{m})$ and dense microvilli. The pharynx is

337 the only region of the gut where we observed cell divisions.

338 A cuticle layer continues from the tentacle surface over the mouth and onto the pharynx, and

339 retains its three-layered structure. An upper layer, thick and felt-like, comprises fine electron-dense

340 strands (antennulae) radiating upwards from the tips of the microvilli. The medial layer comprises a

341 flat skein of electron-dense strands radiating horizontally from the microvilli halfway along their

342 length (cf. the analogous but subterminally located layer on the tentacles). The third, bottom layer is

343 fine-grained, homogeneous and electron-lucent. Cell cytoplasm contains an elongated nucleus,

344 mitochondria and rER, but no major vacuoles.

345 In the distal half of the pharynx, pharyngeal ridges can bear ciliation. In H. robusta, H. sp. 2

346 and Horneridae gen. sp. 3 this comprises 5-15 multiciliated cells located approximately in the center

347 of each ridge. Each cilium has a single kinetosome, axial and lateral rootlets and a proximally 
348

349

350

351

352

353

354

355

356

357

358

359

360

361

362

363

364

365

366

367

368

369

370

371

372

373

374

375

376

377

378

379

directed basal foot. In $H$. sp. 1 the number is smaller: from 1 to 7 cells. We were unable to positively confirm that they are monociliated, but the basal apparatus includes two kinetosomes instead of one, which implies monociliated condition.

In the proximal portions cilia are missing in all of the species. The ridges tend to be higher and the pharyngeal lumen smaller.

The pharynx is supplied with basiepithelial nerves. In H. robusta there are two or three major pharyngeal nerves, each located underneath the ridges. In $H$. sp. 2 we found a large and variable number of nerves. In addition, this species alone possessed large intercellular spaces, which can be mistaken for vacuoles in semi-thin sections.

Pharyngeal epithelium rests on a delicate ECM with embedded cross-striated circular muscles (Figure 8b). This layer of musculature is a seamless continuation of the oral sphincter. On the outside the pharynx is also supplied with irregular longitudinal muscles (10-20 fibers per cell; Figure 8b). In $H$. robusta and $H$. sp. 1 the number is low $(\sim 5)$, whereas in $H$. sp. 2 these muscles are more numerous ( 20).

A very narrow constriction or valve, supplied with powerful circular muscles, separates the pharynx from a short cardia (Figure $8 \mathrm{a}$, inset). The cardia is lined by cuboidal epithelial cells $\sim 4-5 \mu \mathrm{m}$ tall (Figure 8c). Apical surfaces of these cells have no ciliation but microvilli are present. The circular and longitudinal musculature present in the pharynx continues onto the outer cardial wall (Figure 8c).

The caecum is the largest portion of the gut (Figures 8a, 9). Caecal cells are typically tall $(\sim 10-20 \mu \mathrm{m})$ and bear no ciliation. In the distal part of the caecum the cells often have electron-dark cytoplasm, low-contrast nuclei and almost no inclusions. In the medial part of the caecum some cells engage in active biosynthesis as evidenced by enlarged perinuclear spaces and numerous rER cisternae, often enlarged or else forming densely packed fields and occupying nearly all the cytoplasm. More proximally, a different type of cell becomes dominant. These cells have electronlight cytoplasm, high-contrast nuclei and great numbers of large (up to $5 \mu \mathrm{m}$ in diameter) organelles which we interpret as secondary lysosomes with a variety of electron-lucent and electron-dense contents (Figure 9a,d). Towards the proximal end of the caecum, the number of cells with secondary lysosomes grows, and the content of the latter becomes more granulated and electron-dark. On the sections examined by transmitted-light microscopy these organelles have a distinctive orange-brown coloration, indicating the presence of lipofuscin. On any given cross-section one may see up to 20 such vacuoles per cell. Nevertheless, cells with active rER are also present throughout the proximal part of the gut and particularly near the origin of the funiculus (Figure 9a,d, inset). At no point in the 
380 caecum did we observe cell divisions. The outer caecum wall lacks prominent circular musculature.

381 Several diagonal and $\sim 30$ delicate longitudinal muscles encase the caecum between the ECM and 382 coelothelium.

383 The pylorus is a relatively short segment of the gut ( 10-20 cells in length; roughly

384 equivalent to cardia), lined by cylindrical to cuboidal cells bearing dense ciliary and microvillar cover

385 (Figure 9a,c). The basal complex of a pyloric cilium includes a very prominent axial rootlet, a basal

386 foot and short lateral rootlet (Figure 9c, inset). The basal complexes are arranged somewhat

387 irregularly, with basal feet of neighboring cilia pointing in different directions. On the outside the

388 pylorus is surrounded by fine ECM, delicate longitudinal muscles, and coelothelium.

389 The pylorus transitions to the rectum without a valve (Figure 9a). The cells lining the rectum

390 are relatively large and cuboidal $(\sim 6 \mu \mathrm{m})$, usually without distinctive apical structures (Figure 9a,b).

391 Some of these cells tend to have electron-lucent cytoplasm and large secondary lysosomes

392 reminiscent of the caecum wall. Others show signs of active biosynthesis. Outer layers include the

393 same components: ECM, longitudinal muscles, and coelothelium. Interestingly, no distinctive anal

394 sphincter was seen in any of the studied species (Figure 9a, inset).

\subsection{Funiculus and trunk coelom}

The funiculus of the studied hornerids is a solid ECM cord $\sim 4$ by $10 \mu \mathrm{m}$ in cross-section,

398 devoid of either lumen or lacunae (Figure 10). In a relaxed state it is $\sim 250 \mu \mathrm{m}$ long, whereas

399 contracted it is about 50-150 $\mu \mathrm{m}$. Two funicular muscles are adpressed to the outside the ECM cord

400 (Figure 10a,b). At their origin, each muscle cell is anchored to the membranous sac and - through it

401 - to the cystid at the funicular attachment zone (Figure 10c). In addition, they are attached to the

402 ECM cord of the funiculus itself with hemidesmosomes. The ECM of the funiculus joins seamlessly

403 with the ECM of the outer gut wall (Figure 10b) as well as the membranous sac (Figure 10c). The

404 funicular attachment footprint is $40-50 \mu \mathrm{m}$ in proximal-distal direction and $\sim 30 \mu \mathrm{m}$ laterally. We

405 detected no mural pores on the cystid wall at the point of attachment, which suggests that the

406 funiculus does not take part in interzooidal transport or neural connectivity.

407 At the base of the funiculus we sometimes saw a group of cells dissimilar from gut cells (Figure

408 10b). We did not see specific insertion points of the funicular muscles into the gut wall, so it is

409 possible that they continue along the outer surface of the gut as longitudinal caecum muscles (as in

410 Crisia eburnea, Worsaae et al., 2018). If so, they cannot be distinguished from other caecum

411 musculature. 

noticeable in the distalmost portion of the membranous sac of retracted polypides (Figure 10a). In

414 addition to cells, we also noted numerous membrane-bounded vesicles (potential cell debris).

415

416

417

\section{Discussion}

Polypides of the four studied hornerid species have a relatively typical anatomy compared to other cyclostomates. Except for the funiculus, the broad structure of the organs and body compartmentalization, as well as some ultrastructural details, are in agreement with studies on other species and often show clear functional linkages.

Gross tentacle structure of our studied species is in line with all other examined cyclostomates, although, like other members of this order, hornerids lack ciliated pits, recently explored in gymnolaemates (Shunatova \& Borisenko, 2020). The general principles of organization of the basal apparatus of lateral-frontal and lateral cilia are relatively conservative in Bryozoa. Lateral-frontal cilia always have two kinetosomes and a combination of axial and diagonal rootlets, arranged similarly relative to the tentacle midline, which implies shared and conserved function (both motile and mechanoreceptive). The differences in basal complexes of Hornera, phylactolaemates and gymolaemates are slight. In Phylactolaemata there is an additional diagonal rootlet, absent in our studied species, whereas freshwater species lack a basal foot which is present in hornerids. Images of the lateral-frontal cilia in Gymnolaemata by Lutaud (1973) show one axial rootlet proceeding from the main kinetosome and going through the groove in the nucleus. An additional kinetosome is displaced toward the tentacle midline. There is a second axial rootlet, arising from this kinetosome and joining the main axial rootlet, an arrangement that is similar to what we have found in hornerids. Finally, a third, diagonal rootlet attaches to the additional kinetosome. Shunatova (2002) also gives excellent descriptions of the basal apparatus of B-cells in Rhamphostomella ovata and Eucratea loricata. The main kinetosome gives rise to one axial rootlet and a basal foot pointing frontally. The additional kinetosome is also located frontally and gives rise to one axial and two diagonal rootlets (going proximally and distally along the tentacle). In addition, there is a microfilament bundle linking the kinetosomes.

Orientation of the basal feet corresponds to the direction of the active stroke of the motile cilia (e.g., Boisvieux-Ulrich et al., 1985). Although lateral-frontal cilia do not take part in generating water currents, they make occasional flicks in order to intercept and transport particles back into the center 
444 of the feeding current. The location of the basal foot, if present, is in agreement with this view, since

445 it is always pointing frontally, towards the midline of the tentacle.

446 Organization of the lateral cilia in hornerids resembles that of gymnolaemates (Gordon, 1974;

447 Lutaud, 1973; Smith, 1973). Lacking, however, are some of the cytoplasmic anchoring mechanisms

448 found in phylactolaemates, i.e. one of the lateral rootlets and a network of microtubules radiating

449 from the basal feet of lateral cilia (Fawcett 1958, Tamberg and Shunatova 2017). The presence and

450 orientation of the basal feet, however, is universal in all bryozoans studied so far.

451 Abfrontal cilia are also found in all bryozoans and are widely considered to be

452 mechanoreceptive and non-motile. Shunatova and Nielsen (2002) reported only monociliated cells on

453 the abfrontal surfaces of the tentacles in four stenolaemate species (Crisia eburnea, Crisiella

454 producta, Tubulipora flabellaris and Patinella verrucaria). The same authors reported that

455 monociliated cells alternate with multiciliated ones which bear 7-15 non-motile cilia in 17

456 gymnolaemate species. Gordon (1974) also described both single cilia and tufts of ten cilia in the

457 gymnolaemate Cryptosula pallasiana. In Rhamphostomella ovata a basal foot and two rootlets are

458 reported (Shunatova and Nielsen 2002). In phylactolaemates the abfrontal ciliary arrangements are

459 always made of paired monociliated and/or biciliated cells (Tamberg and Shunatova, 2017), giving

460 rise to tufts of three or four cilia (Riisgård et al. 2004, Tamberg and Shunatova, 2017).

461 Ciliated mechanoreceptor cells are known to depolarize when the sensory cilia are displaced

462 in the direction of the basal foot. In other words, the foot projects from the kinetosome in the

463 direction of ciliary movement which excites the cell (Barber and Boyde, 1968). If the abfrontal cilia

464 are indeed mechanoreceptive, we can make inferences about the ciliary displacements they are

465 designed to detect. In Phylactolaemata both upper and lower cells of the abfrontal pair have distal-

466 facing feet, i.e. they preferentially detect being displaced towards the tip of the tentacle.

467 Unfortunately, in Gymnolaemata the direction of the basal feet of the abfrontal cilia has not been

468 described, and in this study, we have not seen basal feet.

469 Although organization of the ciliary basal complexes differs somewhat in cyclostomates,

470 phylactolaemates and gymnolaemates, all these groups share deep structural similarities.

471 Tentacle and lophophoral coeloms are completely separated from the trunk by a delicate

472 unbroken septum. This observation agrees with previous reports on rectangulates, articulates and

473 tubuliporines (Shunatova \& Tamberg, 2019).

474 The tentacle sheath of all bryozoans is supplied with longitudinal and sometimes circular

475 musculature. The role of these muscles seems to reside primarily in the execution of behavioral 
476 reactions, such as scanning (presumably locating a preferred feeding position), optimal positioning of

477 the lophophores around the chimney, colonial cleaning and others (see Shunatova and Ostrovsky

4782001,2002 and references therein). In cheilostomatids the everted tentacle sheath is fully revealed

479 above the skeleton, and polypides can perform a variety of inclines, rotations and bends (Winston

480 1978; Shunatova and Ostrovsky 2001, 2002). In cyclostomates, however, only the tentacles protrude

481 from the aperture. With the tentacle sheath hidden in the skeletal tube, its movements are restricted.

482 For instance, Shunatova and Ostrovsky (2001) describe no scanning in any of their studied

483 cyclostomate species (Crisia sp., Crisiella producta, Tubulipora flabellaris, Patinella verrucaria,

484 Disporella hispida). Our observations on living $H$. robusta and $H$. sp. 2 are in good agreement: the

485 position of the lophophore may be adjusted, but only slightly, by minute bends and rotations.

486 Existing studies and present results indicate that cyclostomates have poorly developed

487 musculature of the tentacle sheath, which is not surprising. In 1923, Borg reported no musculature in

488 the tentacle sheath, although later he amended this statement, describing sparse and very delicate

489 circular and longitudinal muscle fibers (Borg, 1926). Nielsen and Pedersen (1979) reported 15 strictly

490 longitudinal muscles in Crisia. Unfortunately, Shunatova and Tamberg (2019) did not describe

491 tentacle sheath in any of their studied species (Tubulipora flabellaris, Patinella verrucaria and

492 Crisiella producta). In this study, examined species of hornerids also have very fine longitudinal

493 musculature in the tentacle sheath.

494 The tentacle sheath and tentacles are the only portions of the cyclostomate polypide body wall

495 where we find cellular and extracellular layers typical of the coelomates. In these regions the

496 epidermis, ECM and coelothelium adhere to form a unified wall.

497 The digestive system of cyclostomates was examined by light microscopic methods primarily

498 by Borg (1926) and later by Worsaae et al. (2018) and Schwaha (2018). At the EM level the primary

499 source of ultrastructural information remains a study by Gordon (1975) on the gymnolaemate

500 Cryptosula pallasiana.

501 The general composition of the gut is typical for cyclostomates with a pharynx, cardia,

502 caecum, pylorus and rectum. Unlike some bryozoans, e.g. Zoobotryon verticillatum (Bullivant \&

503 Bils, 1968), hornerids have no esophagus. Gut epithelium alternates between ciliated and non-

504 ciliated, as well as bearing or lacking microvillar and cuticular cover. Cuticle is present in the mouth

505 and pharynx only. Ciliation is present in the upper pharynx, and, more notably, in the pyloric region.

506 The densely ciliated pylorus in particular resembles that of $C$. pallasiana. According to Gordon

507 (1975), pyloric ciliature in this species generates a rotating rod which compacts the discarded caecum 
508

509

510

511

512 513 2018).

514

515

516

517

518

519

520

521

522

523

524

525

526

527

528

529

530

531

532

533

534

535

536

537

538

539

material. This cannot be checked in hornerids, however, because their opaque skeleton prevents observations of the digestive system at work.

Ciliation of the pharynx is somewhat irregular in hornerids: the number of cilia is unstable and all species except one have confirmed multiciliated myoepithelial cells. This is different from Crisia eburnea with a strict one-cell-wide vertical row of ciliated but non-muscular cells (Worsaae et al.,

Typically for bryozoans, intracellular digestion occurs in the caecum; secondary lysosomes with undigested remains also accumulate in this region. Cells most vigorously engaged in biosynthesis are concentrated in the caecum and rectum, while myoepithelial cells of the pharynx mostly produce suction.

Overall, the pharynx of the studied hornerids is organized as a typical "self-contained" triradial suction pharynx (see Nielsen, 2013 for details) with myoepithelial walls. The same condition, reported previously for Crisia and Cinctipora, and now also for hornerids, is likely universal for Cyclostomatida.

The musculature of the hornerid digestive tract resembles that of other cyclostomates (Worsaae et al., 2018) and, to a degree, C. pallasiana (Gordon, 1975). The circular musculature of the mouth is continuous with that of the pharynx. The buccal dilators insert in the small gaps between the muscles of the oral sphincter and form a circle of radial spokes. The distinct circular musculature of the gut disappears past the cardia, whereas longitudinal muscles surround the entire digestive system. In contrast with the muscular mouth, no anal sphincter was seen.

The funiculus in cyclostomates is defined as a tubular peritoneal cord with longitudinal musculature (Schwaha et al., 2020). In C. eburnea (Worsaae et al., 2018), C. elongata (Carle and Ruppert, 1983), and the hornerid species examined here, there are two funicular muscles, whereas in Cinctipora elegans this number reaches eight (Schwaha et al., 2018).

Our results regarding the internal composition of the funiculus, however, differ from other existing accounts. Carle and Ruppert (1983) reported a fluid-filled lumen in the funiculus of $C$. elongata, and Schwaha et al. (2018) described it in C. elegans as filled with cells and lacking an opening (especially clear in Figure 5). Our findings are in marked contrast with both reports: in hornerids the funiculus contains no cells or openings, the entire core of the funiculus being a solid ECM cord. 
540 funiculus laterally to the membranous sac and, through it, to the mural pores of C. elongata (Carle

541 and Ruppert, 1983) remains unreproduced (see review by Schwaha et al., 2020). We also did not see

542 any connections between the funiculus, the membranous sac and the interzooidal pores in any of the

543 studied hornerids. For Hornera robusta in particular, a careful examination of the gap-free SBF SEM

544 dataset confirmed that no such connection exists. The funicular attachment footprint measured in this

545 study far exceeds the cross-section of the funiculus itself. It seems that high tensile stresses are

546 transmitted through the funiculus and are distributed over a large area. We propose contractile

547 function as primary for this organ in hornerids.

548

549

550

551

552

553

554

555

556

557

558

559

560

\section{Acknowledgements}

562 We are most grateful to Abby Smith (University of Otago) for providing organizational support and

563 discussion, and to the master and crew of R.V Polaris II, staff at Portobello Marine Laboratory and

564 the Otago Microscopy and Nanoscale Imaging unit (OMNI), University of Otago. Special thanks go

565 to Hamish Bowman, Kim Currie, Linda Groenewegen, Allan Mitchell, Sharon Lequeux, Richard

566 Easingwood, Amanda Fisher and Matthew Downes. Y.T. gratefully acknowledges support and

567 discussion from Nina Alexeeva (Zoological Institute of the Russian Academy of Science) and

568 funding from a University of Otago Doctoral Scholarship.

569

\section{Conflict of Interest}

571 The authors declare that they have no financial or otherwise conflicts of interest 


\section{Author Contributions}

574 Y.T. designed the study, wrote the manuscript draft and prepared illustrations. Y.T. and P.B. sampled

575 and processed bryozoans. R.N. provided financial and methodological assistance, and processed one

576 of the SBF-SEM samples. Joint efforts went into discussion and editing of the manuscript.

577

\section{Data Availability Statement}

579 The data that support the findings of this study are available from the corresponding author upon

580 reasonable request. 
Tamberg, p. 20

\section{References}

582 Barber, V. C., \& Boyde, A. (1968). Scanning electron microscopic studies of cilia. Zeitschrift für

583 Zellforschung und Mikroskopische Anatomie, 84(2), 269-284.

584 Batson, P. B., \& P. K. Probert. 2000. Bryozoan thickets off Otago Peninsula. Ministry of Fisheries, 585 Wellington.

586 Boardman, R. S. (1983). General features of the class Stenolaemata. Pp. 49-137 in Boardman, R. S.

587 et al., eds. Treatise on Invertebrate Paleontology. Part G: Bryozoa. Geological Society of America, 588 Boulder, Colorado, and University of Kansas, Lawrence.

589 Boardman, R. S. (1998). Reflections on the morphology, anatomy, evolution, and classification of the 590 Class Stenolaemata (Bryozoa). Smithsonian Contributions to Paleobiology. V. 86. Smithsonian 591 Institution Press: Washington.

592 Boardman, R. S., McKinney F. K., (1985). Soft part characters in stenolaemate taxonomy. Pp. 35-44.

593 in Nielsen, C., and G. P. Larwood, eds. Bryozoa: Ordovician to Recent. Olsen \& Olsen,

594 Fredensborg, Denmark.

595 Boardman, R. S., McKinney, F. K., \& Taylor, P. D. (1992). Morphology, anatomy, and systematics

596 of the Cinctiporidae, new family (Bryozoa: Stenolaemata). Smithsonian Contributions to

597 Paleobiology. V. 70. Smithsonian Institution Press: Washington.

598 Boisvieux-Ulrich, E., Laine, M. C., \& Sandoz, D. (1985). The orientation of ciliary basal bodies in

599 quail oviduct is related to the ciliary beating cycle commencement. Biology of the Cell, 55(1-2),

$600 \quad 147-150$.

601 Borg, F., 1926. Studies on recent cyclostomatous Bryozoa. Zoologiska Bidrag från Uppsala, 10, 18160250.

603 Bullivant, J. S., \& Bils, R. F. (1968). The pharyngeal cells of Zoobotryon verticillatum (delle Chiaje) 604 a gymnolaemate bryozoan. New Zealand Journal of Marine and Freshwater Research, 2(3), 438605446.

606 Carle, K. J., \& Ruppert, E. E. (1983). Comparative ultrastructure of the bryozoan funiculus: a blood

607 vessel homologue. Journal of Zoological Systematics and Evolutionary Research, 21(3), 181-193.

608 Deerinck, T.J., Shone, T.M., Bushong, E.A., Ramachandra, R., Peltier, S.T., Ellisman, M.H. (2018).

609 High-performance serial block-face SEM of nonconductive biological samples enabled by focal

610 gas injection-based charge compensation. Journal of Microscopy, 270(2), 142-149.

611 Gordon, D. (1974) Microarchitecture and function of the lophophore in the bryozoan Cryptosula 612 pallasiana. Marine Biology, 27(2), 147-163. 
613 Gordon, D. P. (1975). Ultrastructure and function of the gut of a marine bryozoan. Cahiers de 614 Biologie Marine, 16, 367-382.

615 Fawcett, D. W. (1958). Structural specializations of the cell surface. In S. L. Palay (Ed.), Frontiers in 616 Cytology. New Haven, Yale University Press.

617 The ImageMagick Development Team, 2021. ImageMagick 6.9. URL https://imagemagick.org

618 Inkscape project, 2017. Inkscape 0.92. URL http://www.inkscape.org/.

619 Kremer J.R., D.N. Mastronarde and J.R. McIntosh (1996) Computer visualization of three-

620 dimensional image data using IMOD. Journal of Structural Biology, 116, 71-76.

621 Lutaud, G. (1973) L'innervation du lophophore chez le bryozoaire chilostome Electra pilosa (1.).

622 Zeitschrift fur Zellforschung und mikroskopische Anatomie, 140(2), 217-234.

623 Nielsen, C. (1970). On metamorphosis and ancestrula formation in cyclostomatous bryozoans.

624 Ophelia, 7(2), 217-256.

625 Nielsen, C. (2013). The triradiate sucking pharynx in animal phylogeny. Invertebrate Biology, 626 132(1), 1-13.

627 Nielsen, C., \& Pedersen, K. J. (1979). Cystid structure and protrusion of the polypide in Crisia 628 (Bryozoa, Cyclostomata). Acta Zoologica, 60(2), 65-88.

629 Nielsen, C., \& H. U. Riisgård. 1998. Tentacle structure and filterfeeding in Crisia eburnea and other 630 cyclostomatous bryozoans, with a review of upstream-collecting mechanisms. Marine Ecology 631 Progress Series, 168, 163-186.

632 Riisgård, H.U., Nielsen, K.K., Fuchs, J., Rasniussen, B.F., Obst, M. \& Funch, P. (2004) Ciliary 633 feeding structures and particle capture mechanism in the freshwater bryozoan Plumatella repens 634 (Phylactolaemata). Invertebrate Biology, 123, 156-167.

635 Schäfer, P. 1985. Significance of soft part morphology in the classification of recent tubuliporoid 636 cyclostomes. Pp. 273-284 in Nielsen, C., and G. P. Larwood (Eds.), Bryozoa: Ordovician to 637 Recent. Olsen \& Olsen, Fredenborg, Denmark.

638 Schwaha, T. F., Handschuh, S., Ostrovsky, A. N., \& Wanninger, A. (2018). Morphology of the 639 bryozoan Cinctipora elegans (Cyclostomata, Cinctiporidae) with first data on its sexual 640 reproduction and the cyclostome neuro-muscular system. BMC Evolutionary Biology, 18(1), 92.

641 Schwaha, T. F., Ostrovsky, A. N., \& Wanninger, A. (2020). Key novelties in the evolution of the 642 aquatic colonial phylum Bryozoa: evidence from soft body morphology. Biological Reviews, $64395(3), 696-729$. 
644 Shunatova, N. N. (2002). The feeding behavior and features of the morphological and functional 645 organization of the feeding apparatus in marine bryozoans (Bryozoa, Gymnolaemata) [Candidate 646 of Biological Sciences Dissertation]. St. Petersburg (Russia): St. Petersburg State University, 254 647 p. [in Russian]

648 Shunatova, N., \& Borisenko, I. (2020). Proliferating activity in a bryozoan lophophore. PeerJ, 8, 649 e9179.

650 Shunatova, N. N., \& Nielsen, C. (2002). Putative sensory structures in marine bryozoans.

651 Invertebrate Biology, 121(3), 262-270.

652 Shunatova, N. N., \& Ostrovsky, A. N. (2001). Individual autozooidal behaviour and feeding in 653 marine bryozoans. Sarsia, 86, 113-142.

654 Shunatova, N., \& Ostrovsky, A. (2002). Group autozooidal behaviour and chimneys in marine 655 bryozoans. Marine Biology, 140(3), 503-518.

656 Shunatova, N., \& Tamberg, Y. (2019). Body cavities in bryozoans: functional and phylogenetic 657 implications. Journal of Morphology, 280(9), 1332-1358.

658 Smith, L.W. (1973) Ultrastructure of the tentacles of Flustrellidra hispida (Fabricius). Pp 335-342 in 659 Larwood G. P. (Ed.), Living and fossil Bryozoa. Academic Press, New York

660 Tamberg, Y., \& N. Shunatova. 2017. Tentacle structure in freshwater bryozoans. Journal of 661 Morphology, 278, 718-733.

662 Tamberg, Y., \& Smith, A. M. (2020). In search of predictive models for stenolaemate morphometry 663 across the skeletal-polypide divide. Paleobiology, 46, 218-236.

664 Temereva, E. N., \& Kosevich, I. A. (2018). The nervous system in the cyclostome bryozoan Crisia 665 eburnea as revealed by transmission electron and confocal laser scanning microscopy. Frontiers in $666 \quad$ zoology, 15(1), 48.

667 Waeschenbach, A., Taylor, P. D., \& Littlewood, D. T. J. (2012). A molecular phylogeny of 668 bryozoans. Molecular phylogenetics and evolution, 62(2), 718-735.

669 Winston, J. E. (1978). Polypide morphology and feeding behavior in marine ectoprocts. Bulletin of 670 Marine Science, 28(1), 1-31.

671 Worsaae, K., Frykman, T., \& Nielsen, C. (2018). The neuromuscular system of the cyclostome 672 bryozoan Crisia eburnea (Linnaeus, 1758). Acta Zoologica, 101(2), 133-146. 


\section{Figure captions}

674

675 Figure 1. Schematic drawing of the protruded hornerid zooid.

676

677 Arrowheads, membranous sac-to-cystid attachments shared by all studied species

678

679

680 Figure 2. Ultrastructure of hornerid tentacles. (a) Schematic drawing of a tentacle cross-section. (b)

681 Cross-section through the middle part of a protruded tentacle (H. sp. 2). (c) 3D model of the lateral-

682 frontal ciliary basal complex. (d) Transverse section of a lateral-frontal cell showing ciliary basal

683 apparatus (H. robusta, tentacle midline on the left). (e) Oblique frontal section of the tentacle

684 showing frontal microvilli and a double row of lateral-frontal cilia (H. sp. 2). (f) Transverse section of

685 lateral cells showing the basal apparatus of basal cilia and cell contacts (H. robusta, frontal side of the

686 tentacle on the left). (g) Cross-section of an abfrontal cell showing basal apparatus of the abfrontal

687 cilia (H. robusta, apical surface at the bottom). (h) Cross-section showing the abfrontal part of the

688 tentacle, abfrontal and abfrontal-lateral nerves, and abfrontal cilium (H. robusta, abfrontal surface on

689 the left).

690

691 A, frontal cell of tentacle epidermis; B, lateral-frontal cell; C, frontal-lateral cell; D, lateral cell; E,

692 abfrontal-lateral cell; F', intermittent abfrontal cell; afm, abfrontal tentacle muscle; afn, abfrontal

693 nerve; c, cuticle; ECM, extracellular matrix; fm, frontal tentacle muscle; fn, frontal nerve; lafn,

694 abfrontal-lateral nerve; lfn, lateral-frontal nerve; pc, peritoneal cell; **, lophophore coelom; black

695 arrowhead, abfrontal-lateral nerve; double back arrowhead, abfrontal cilium; white arrowhead,

696 septate junction

697

698

699 Figure 3. Lophophore base and mouth region. (a) Schematic drawing of a sagittal section through the

700 lophophore base. Black dotted line shows the approximate position of the section in (b). (b) Obliquely

701 transverse section through the zooid tube (white dotted line) and the polypide at the level of the

702 mouth (H. sp. 2). 
704 ECM, extracellular matrix; g, ganglion; ms, membranous sac; os, oral sphincter, continuous with

705 circular muscles of the pharynx; rm, retractor muscle; s, septum; ts, tentacle sheath; *, exosaccal

706 cavity; $* *$, lophophore coelom; $* * *$, endosaccal cavity $=$ trunk coelom

709 Figure 4. Lophophore base and mouth region. (a) Cross-section of merging tentacles of a protruded 710 polypide (H. sp. 2, frontal/oral side up). (b) Midsagittal section through the mouth and lophophore 711 base of a retracted polypide showing the origin of the tentacle sheath, the thick ECM collar at the 712 lophophore base, oral and pharyngeal sphincter and lophophore-trunk septum (H. robusta). Dotted 713 line represents the approximate location of section (c). (c) Obliquely transverse section through the 714 tentacle base and mouth region (H. robusta, all ECM blue, nerves green). (d) Cross-section through

715 the oral sphincter showing ECM of the lophophore roof folding over the muscles and continuing onto

716 the pharyngeal wall ( $H$. robusta). (e) Sagittal section through the mouth showing ring nerve and

717 buccal dilator (H. robusta).

719 bd, buccal dilator; lECM, extracellular matrix at the base of the lophophore; ms, membranous sac; os, 720 oral sphincter, continuous with circular muscles of the pharynx; ph, pharynx; phe, pharyngeal

721 epithelium; rm, retractor muscle; rn, ring nerve; ts, tentacle sheath; *, exosaccal cavity; **,

722 lophophore coelom; ***, endosaccal cavity; black arrowhead, ECM of the lophophore roof; white

723 arrowhead, lophophore-trunk septum; double white arrowhead, lophophoral insertion of retractor

724 muscles

727 Figure 5. Ganglion. (a) Cross-section through the zooid tube with retracted polypide at the level of 728 the ganglion, showing the distal portions of the ganglion lobes (Hornerid gen. sp3). (b) Midsagittal

729 section through the ganglion of a retracted polypide (H. robusta, ganglion surrounded by black dotted 730 line, neuropile - by white dotted line), (c) Cross-section of a retracted polypide through the ganglion, 731 showing buccal dilator, oral sphincter, lophophore-trunk septum and neuropile (H. sp. 2).

733 afECM, abfrontal tentacle ECM; bd, buccal dilator; fECM, frontal tentacle ECM; g, ganglion; gl, 734 ganglion lobe; ms, membranous sac; rm, retractor muscle; ts, tentacle sheath; os, oral sphincter; ${ }^{*}$ 735 exosaccal cavity; black arrowhead, ECM of the septum; white arrowhead, ring nerve; black double 
736 arrowhead, distal part of the rectum; white double arrowhead, hemidesmosomes attaching buccal

737 dilator to the oral ECM

738

739

740 Figure 6. Tentacle sheath. (a) Obliquely frontal section through the protruded polypide (H. sp. 2). (b)

741 Longitudinal section through the base of the tentacle sheath in a retracted polypide, showing lack of

742 cuticle on the tentacle sheath epidermis (H. robusta). Inset (H. sp. 1) shows septate cell junction

743 similar to the black frame in figure (b). (c) Transverse section through the tentacle sheath of a

744 protruded polypide showing longitudinal muscle (H. sp. 2 endosaccal cavity above, vestibular space

745 below).

746

747 c, cardia; ca, caecum; ECM, extracellular matrix; ph, pharynx; rm, retractor muscle; ts, tentacle

748 sheath; ***, endosaccal cavity

749

750

751 Figure 7. Retractor muscles. (a) Sagittal section through colony branch showing two expanded

752 (distal) and one retracted polypide (proximal), illustrating retractor muscles in the relaxed and

753 contracted state respectively (H. sp. 2). (b) Transverse section through the pharyngeal region of the

754 retracted polypide showing skeletal origins of retractor muscles (H. sp. 2). (c) Details of lophophoral

755 insertion of the retractor muscle showing hemidesmosomes (H. sp. 1). (d) Cross-section through the

756 medial part of the contracted retractor muscle showing nuclear indentations (H. sp. 2).

758 lECM, lophophoral extracellular matrix; msECM, extracellular matrix of the membranous sac; rm,

759 retractor muscle; *, exosaccal cavity; ***, endosaccal cavity; black arrowhead, skeletal attachments

760 of retractor muscles; double black arrowhead, lophophoral insertion of retractor muscles; white

761 arrowhead, hemidesmosomes at lophophoral insertion; double white arrowhead, membranous sac

762 musculature

763

764

765 Figure 8. Digestive system: downward branch. (a) Oblique sagittal section through the partially

766 retracted polypide showing digestive system. Black dotted lines indicate approximate locations of the

767 cross-sections (H. robusta). (b) Cross-section through the medial part of the pharynx of a retracted 
768 polypide showing myofibrils in the pharyngeal epithelium, circular and longitudinal muscles of the 769 pharynx wall (H. robusta). (c) Cross-section through the cardia of a protruded polypide (H. sp. 2);

770 inset shows cross-section of a contracted pharyngeal-cardial valve (H. sp. 1).

771

772 c, cardia; ca, caecum; m, mouth; ms, membranous sac; p, pylorus; ph, pharynx; r, rectum; rm,

773 retractor muscle; t, tentacle; *, exosaccal cavity; ***, endosaccal cavity; black arrowhead, circular

774 musculature of pharynx and cardia; double black arrowhead, non-muscular cell in pharyngeal

775 epithelium; white arrowhead, lophophoral insertion of retractor muscles; double white arrowhead,

776 longitudinal muscles of pharynx and cardia

777

778

779 Figure 9. Digestive system: upward branch. (a) Sagittal section through retracted polypide showing

780 digestive system. Black dotted lines indicate approximate locations of the cross-sections (H. robusta).

781 Inset presents rectum near anus (Horneridae gen. sp. 3). (b) Cross-section of the rectum with a fecal

782 pellet inside (H. robusta). (c) Cross-section of the pylorus (Horneridae gen. sp. 3). Black frame

783 corresponds to the tilted area, similar to the inset. Inset shows details of pyloric cilia and microvilli

784 (H. sp. 1). (d) Cross-section through the proximal part of caecum, showing active biosynthetic

785 apparatus and large secondary lysosomes (H. robusta). Black frame corresponds to the area similar to

786 the inset. Inset demonstrates numerous rER cisternae (Horneridae gen. sp. 3).

788 c, cardia; ca, caecum; m, mouth: ms, membranous sac; p, pylorus; ph, pharynx; r, rectum; rm,

789 retractor muscle; t, tentacle; *, exosaccal cavity; ***, endosaccal cavity; black arrowhead,

790 longitudinal gut musculature; double black arrowhead, circular muscles of the pharynx; white

791 arrowhead, secondary lysosomes; double white arrowhead, basal feet of pyloric cilia

794 Figure 10. Ultrastructure of the funiculus. (a) Cross-section through the zooidal chamber at the 795 proximal end of the membranous sac and funiculus, showing the distalmost edge of the funicular 796 attachment ligament (black arrowheads) (H. sp. 2). (b) Longitudinal section through the proximal tip 797 of the gut and the origin of funiculus (H. robusta). (c) Longitudinal section through the funicular 798 attachment (H. robusta, proximal direction on the left). 
bioRxiv preprint doi: https://doi.org/10.1101/2021.03.09.433978; this version posted March 10, 2021. The copyright holder for this preprint (which was not certified by peer review) is the author/funder. All rights reserved. No reuse allowed without permission.

800 ECM, extracellular matrix; fm, funicular muscle; ms, membranous sac; black arrowhead, tendon cell

801 of the funicular attachment; white arrowhead, sperm cell; *, exosaccal cavity 
tentacle crown

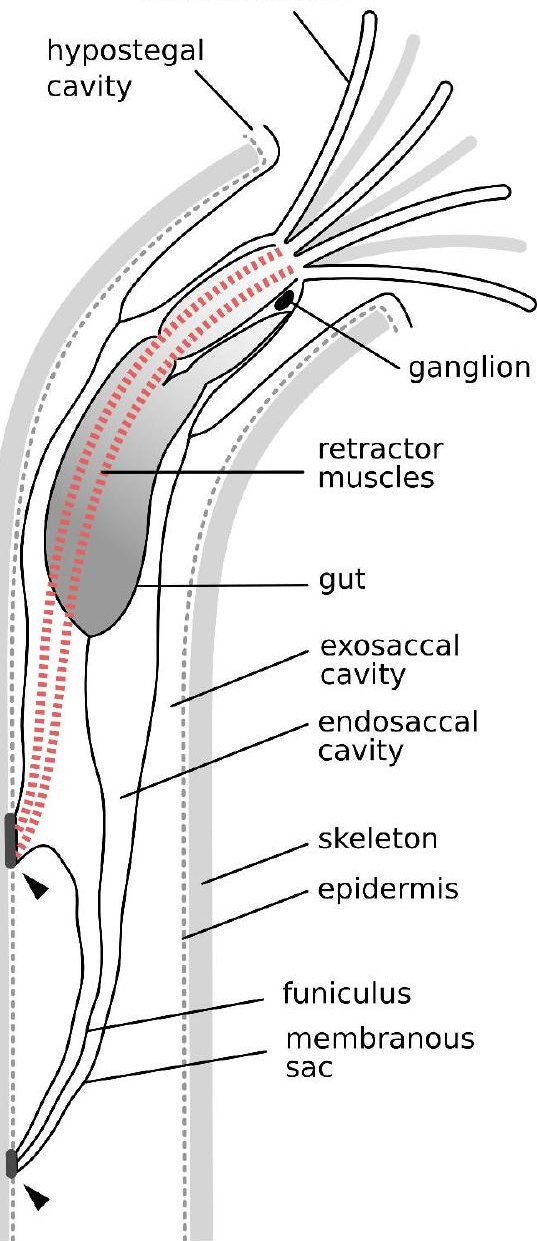




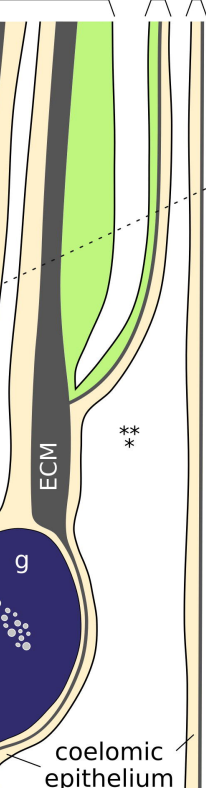

㓤
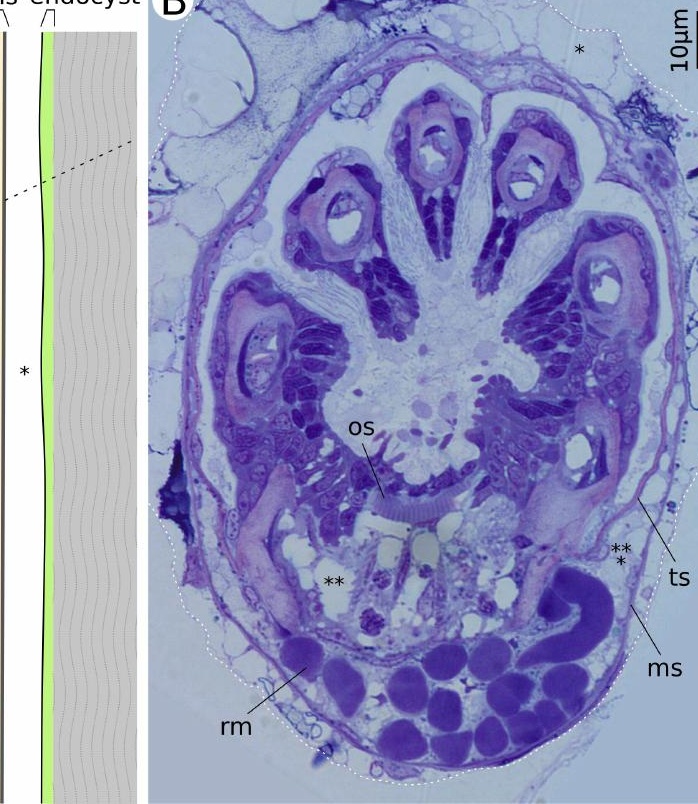


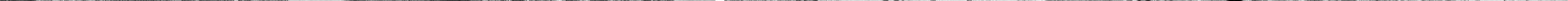


B 00 at -2
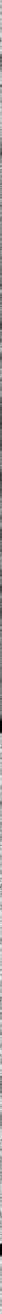

**
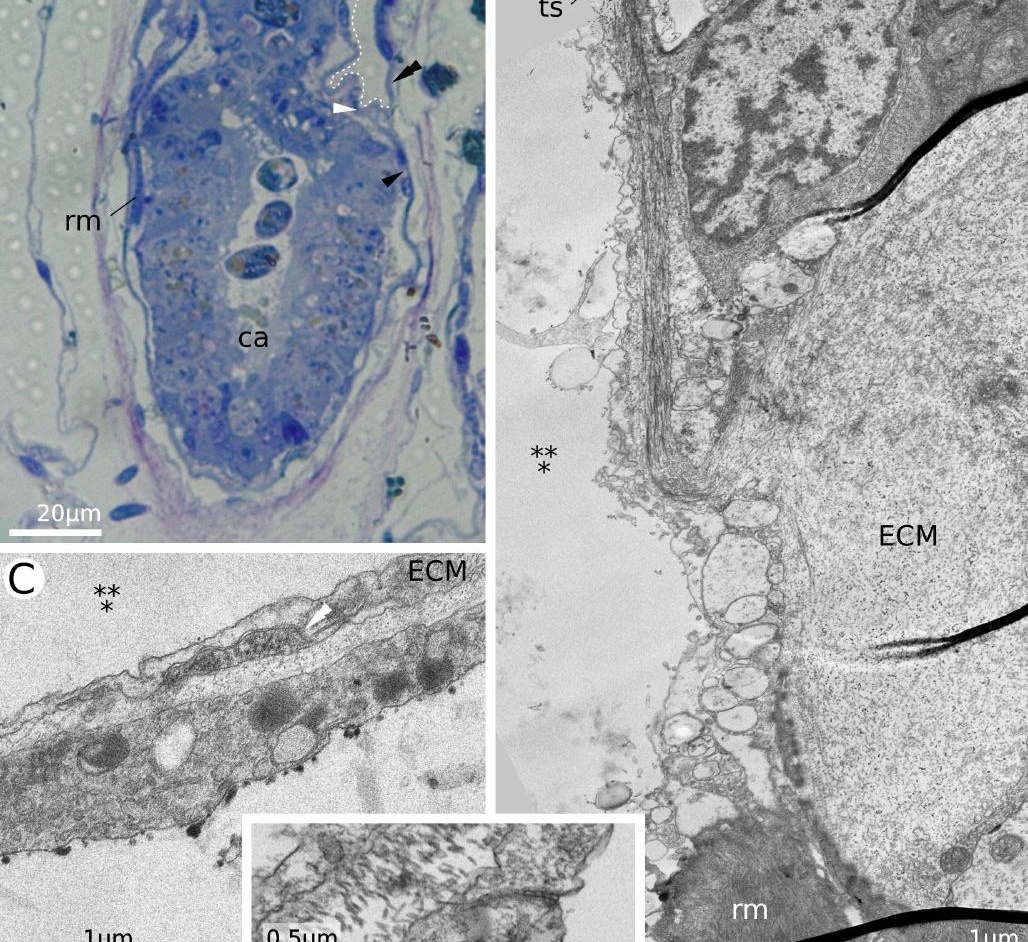

$1 \mu \mathrm{m}$ 


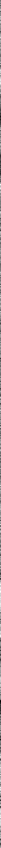

장 0001

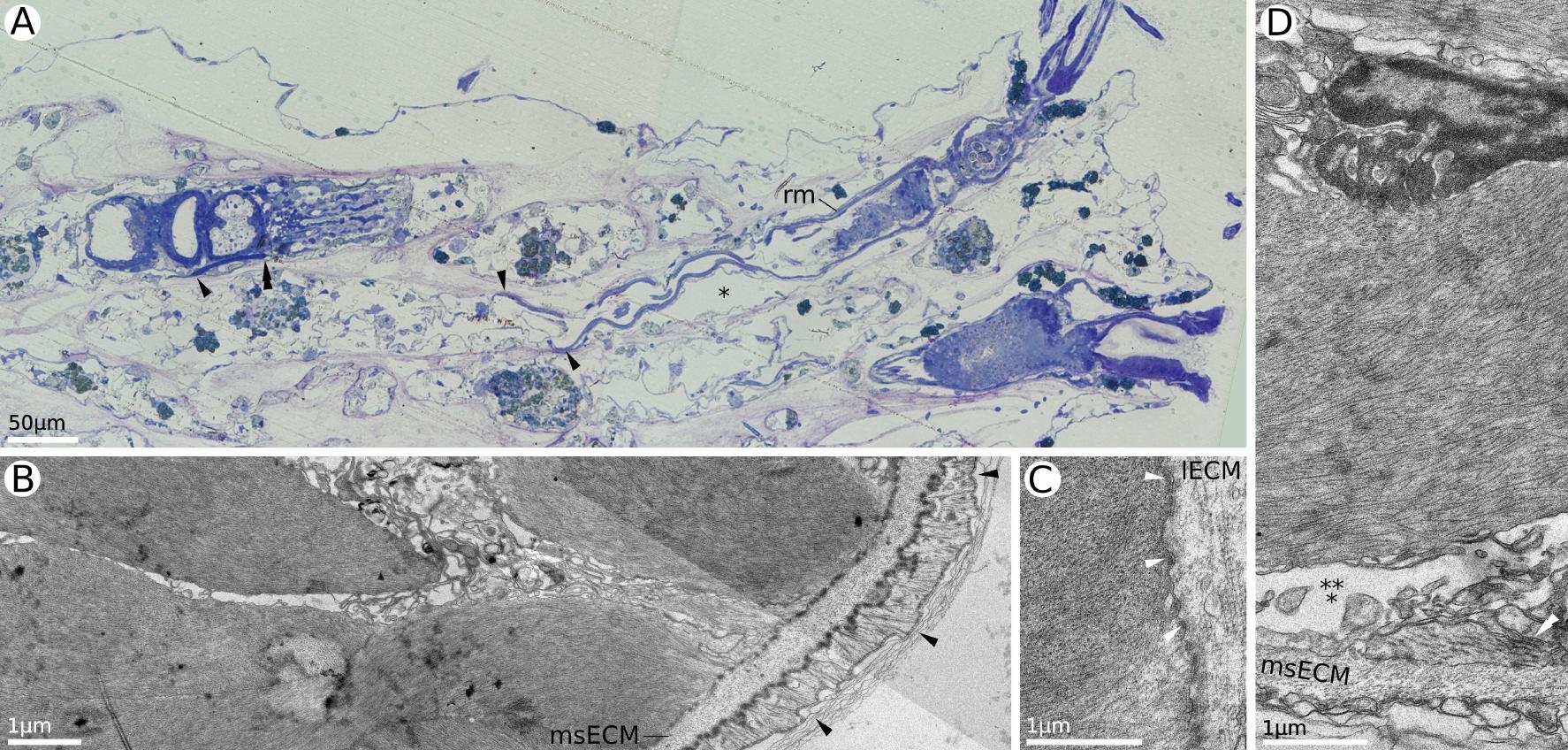

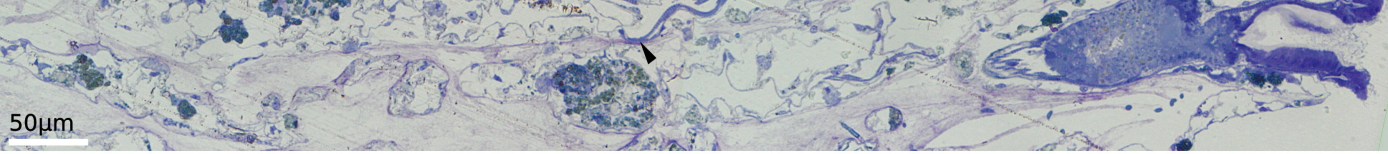

B
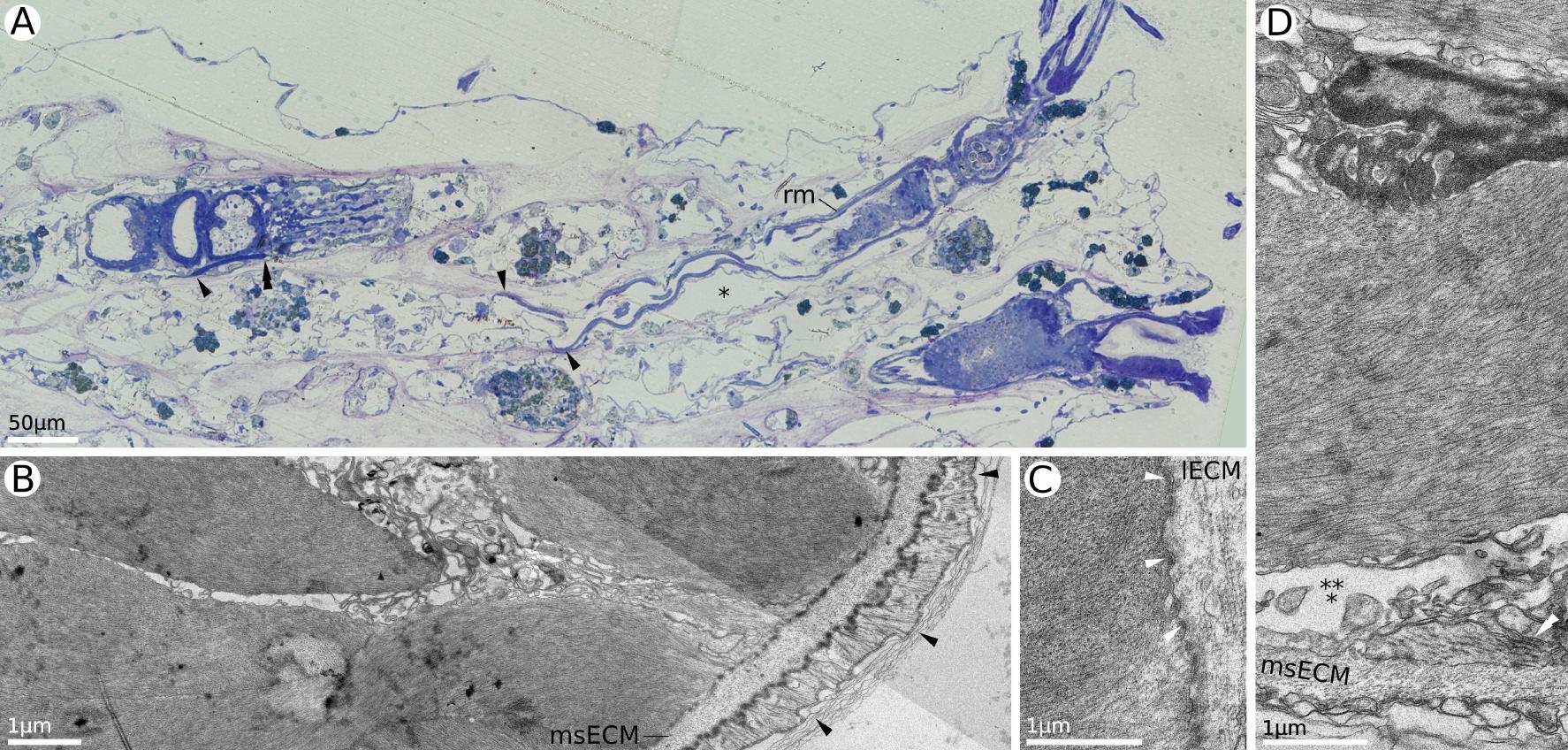
MsECM - st

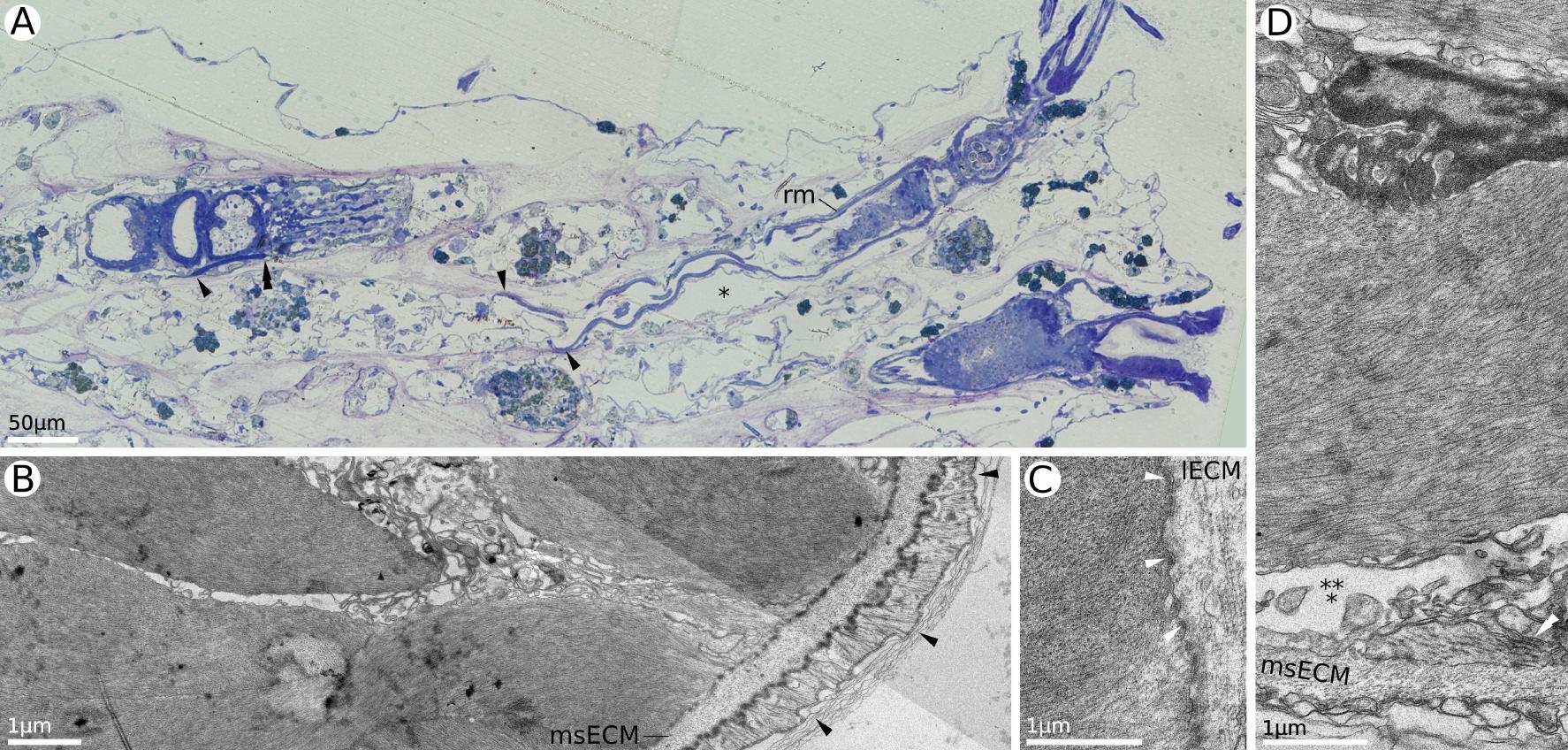

M

列

are

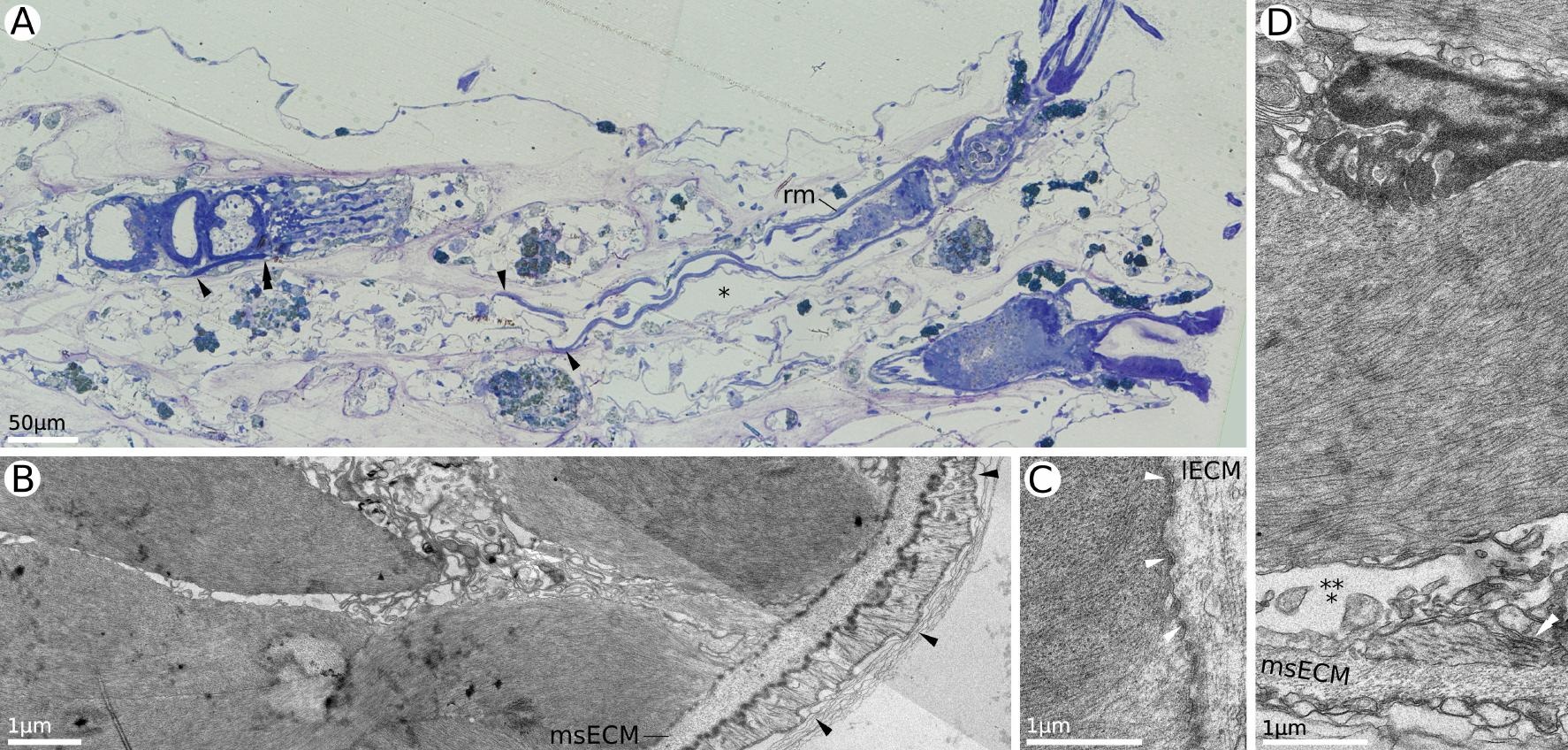

-

2.

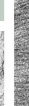
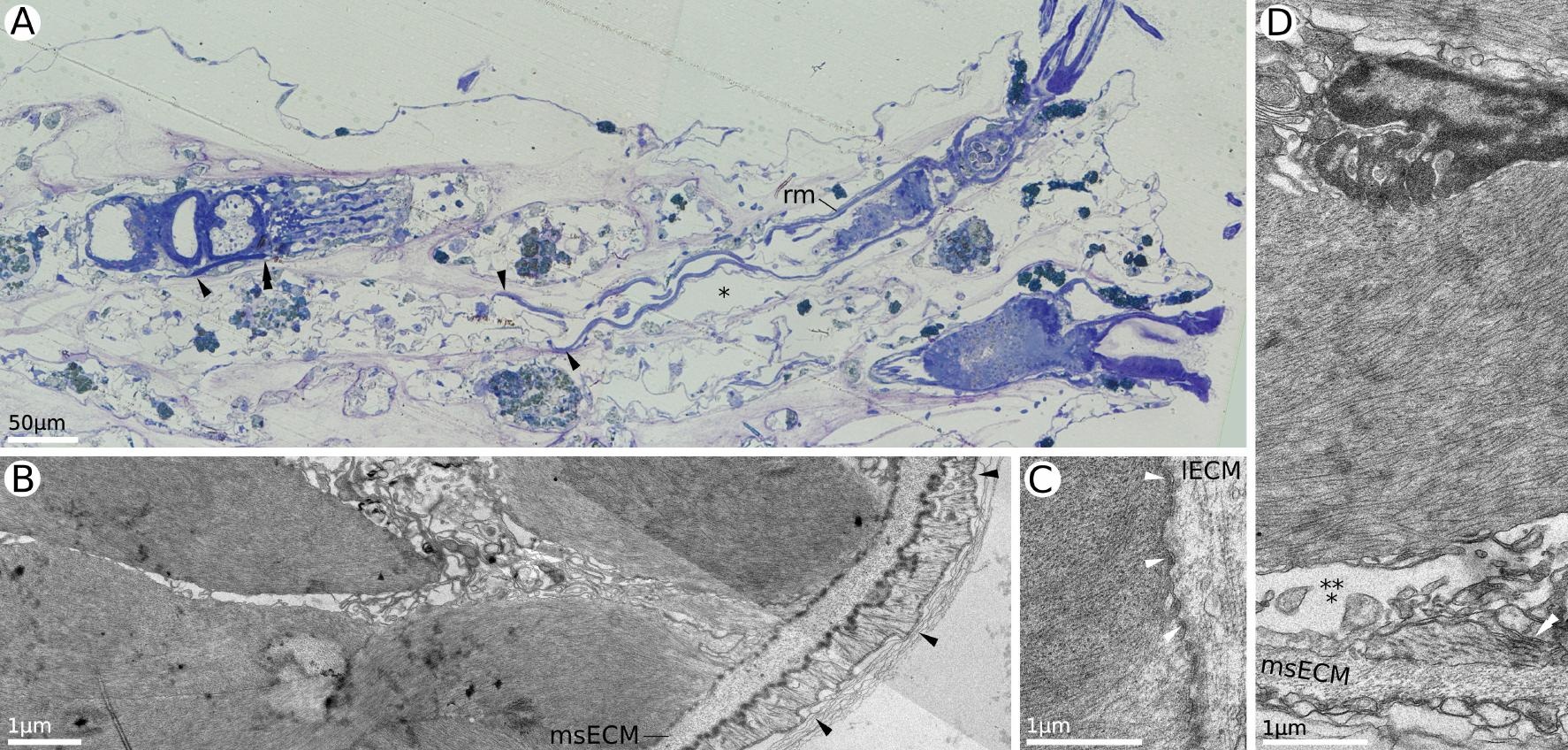

14in

$1 \mu \mathrm{m}$ 
A 1711479 WNa chis 1

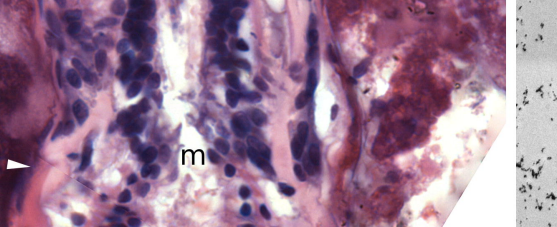

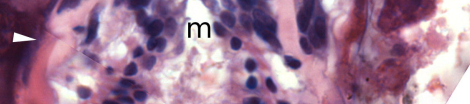
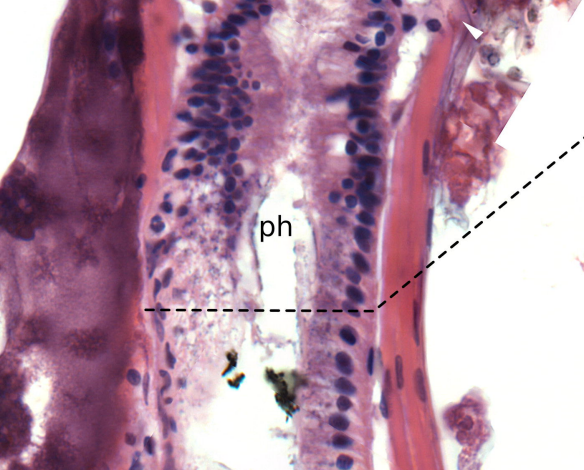

(s)

xary

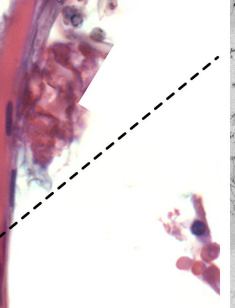

max

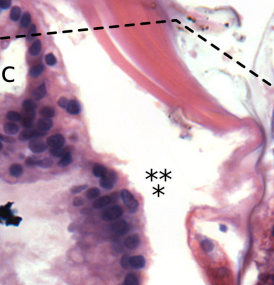

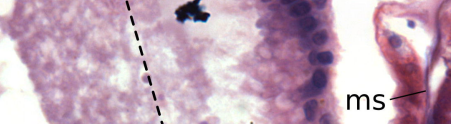

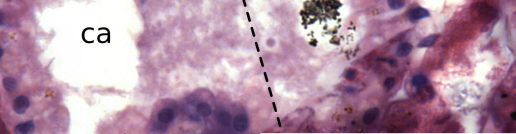

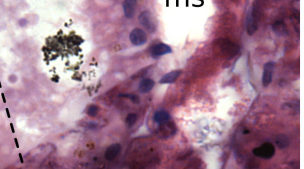

(2)

in 300 -
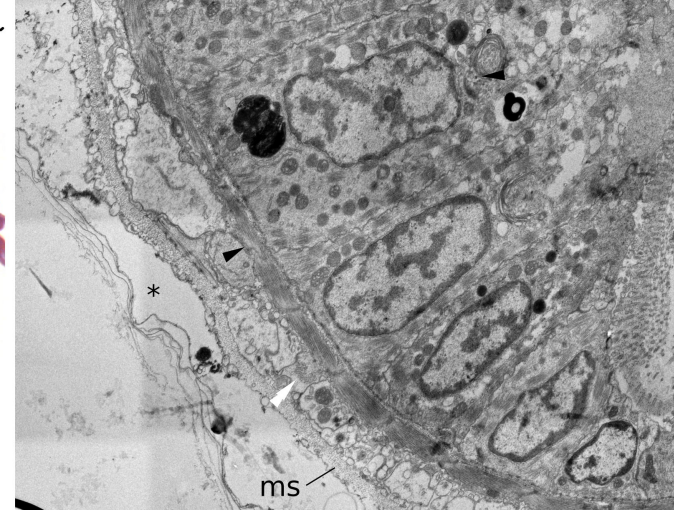

(

Wid

ars

(2)

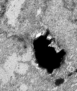

s.

1.

is

4

208.

Hoge

a. 60

1.6 $=3$

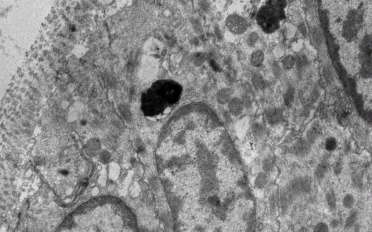
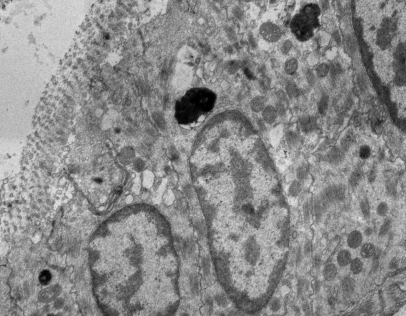

39

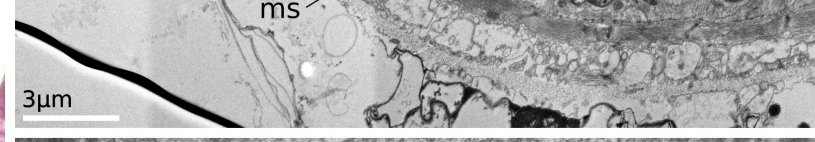

10

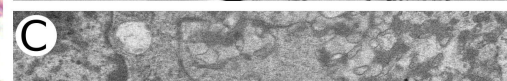

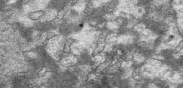

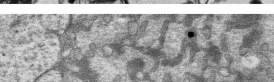

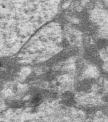

D.

se.

2.25

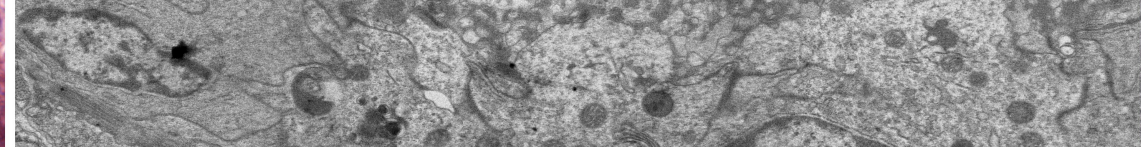

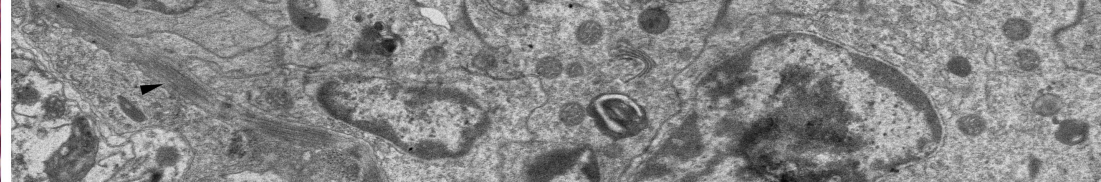

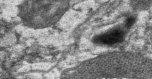
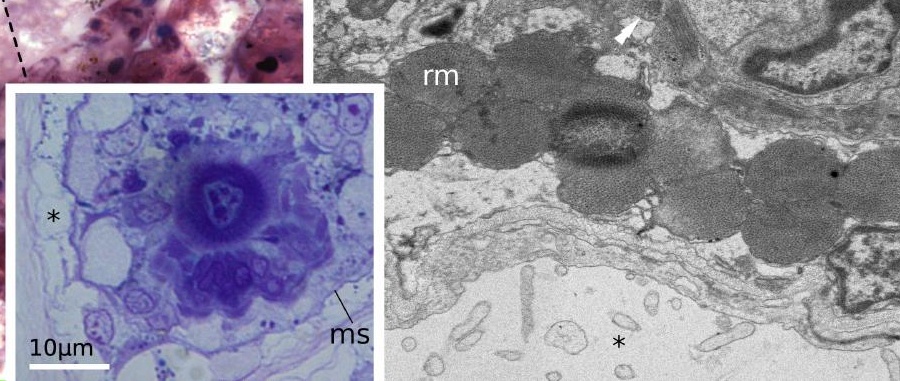

$\operatorname{lic}^{2}, 2, \cos ^{2}$

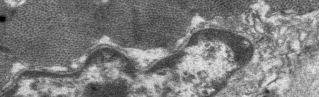
(x) 
$A_{1},-00$

(x)

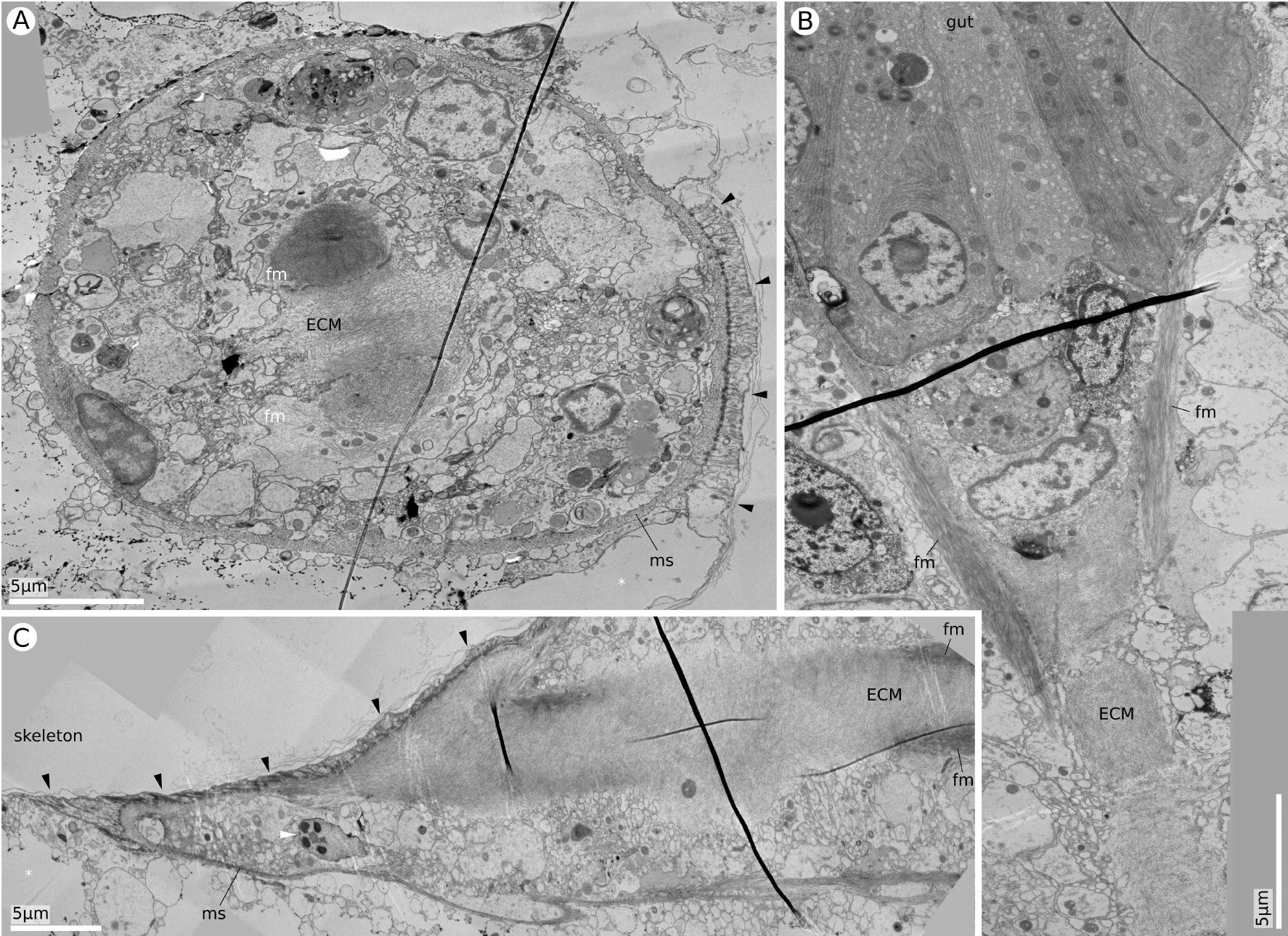

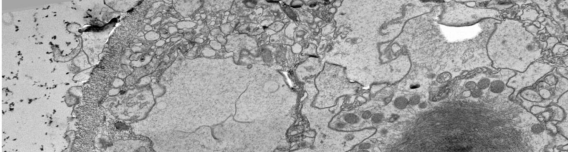

50 to

(3)

,

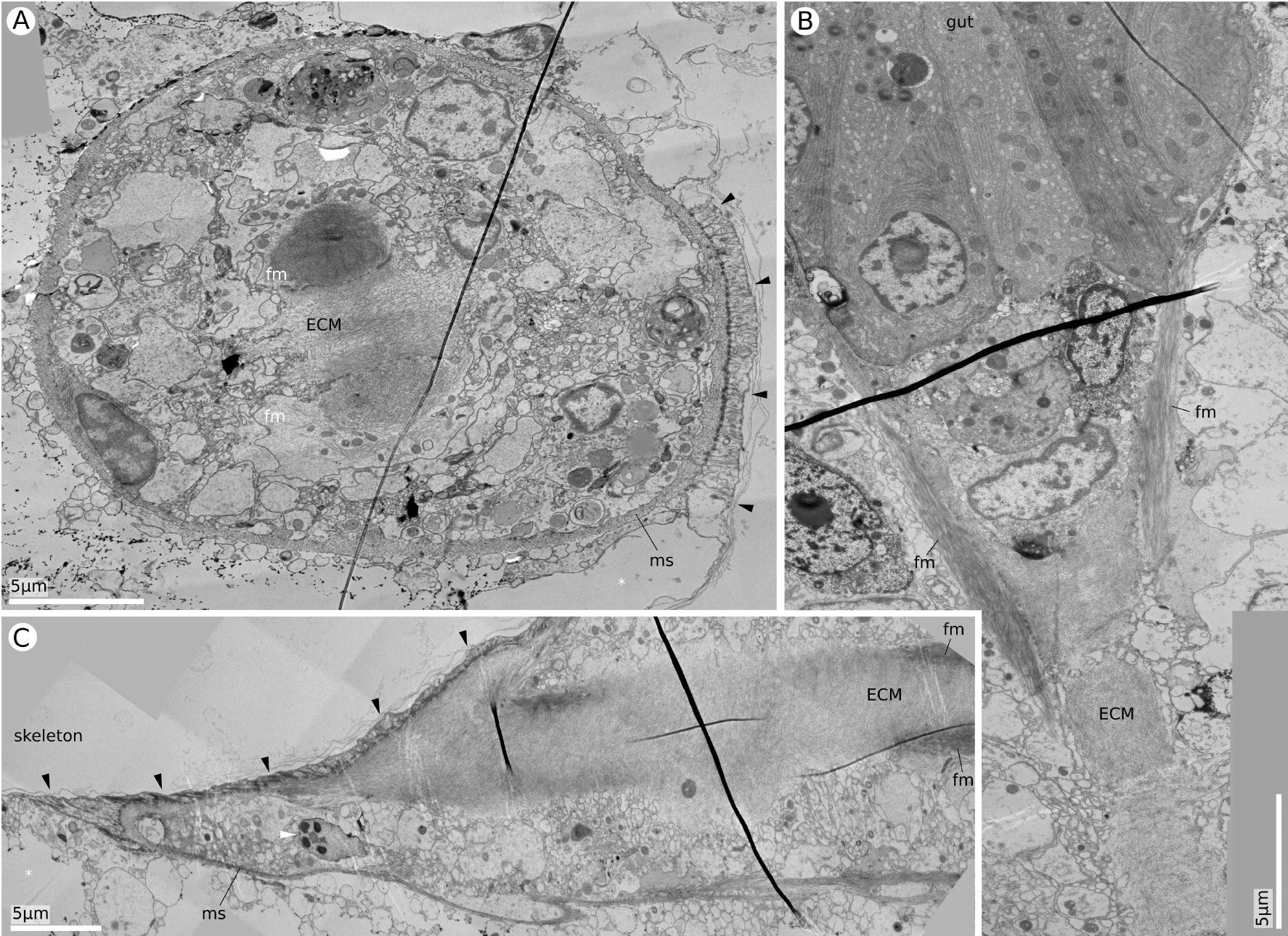

C

$5 \mu \mathrm{m}$

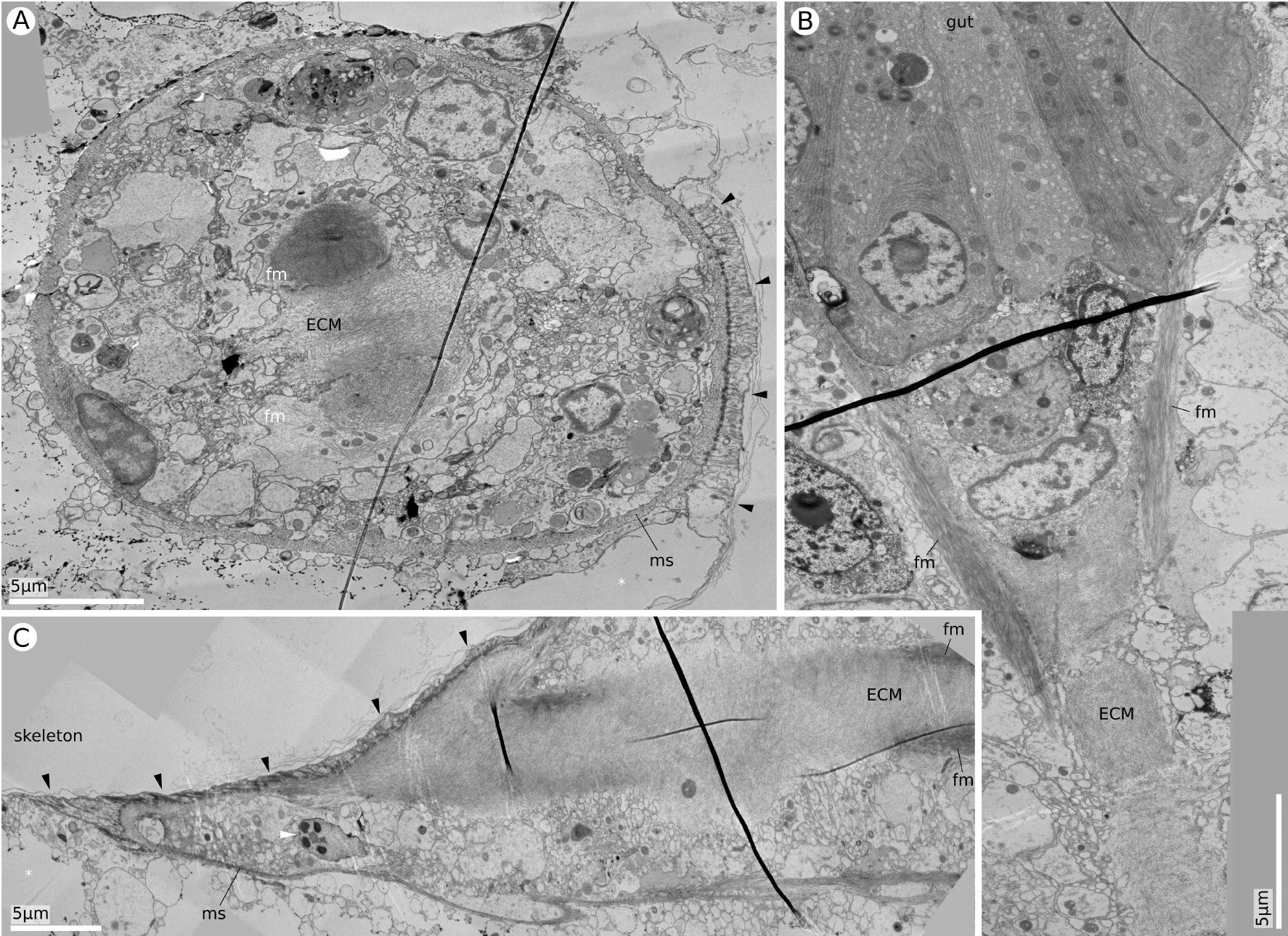

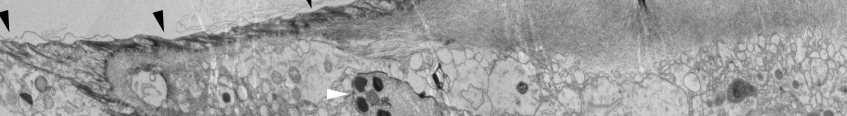
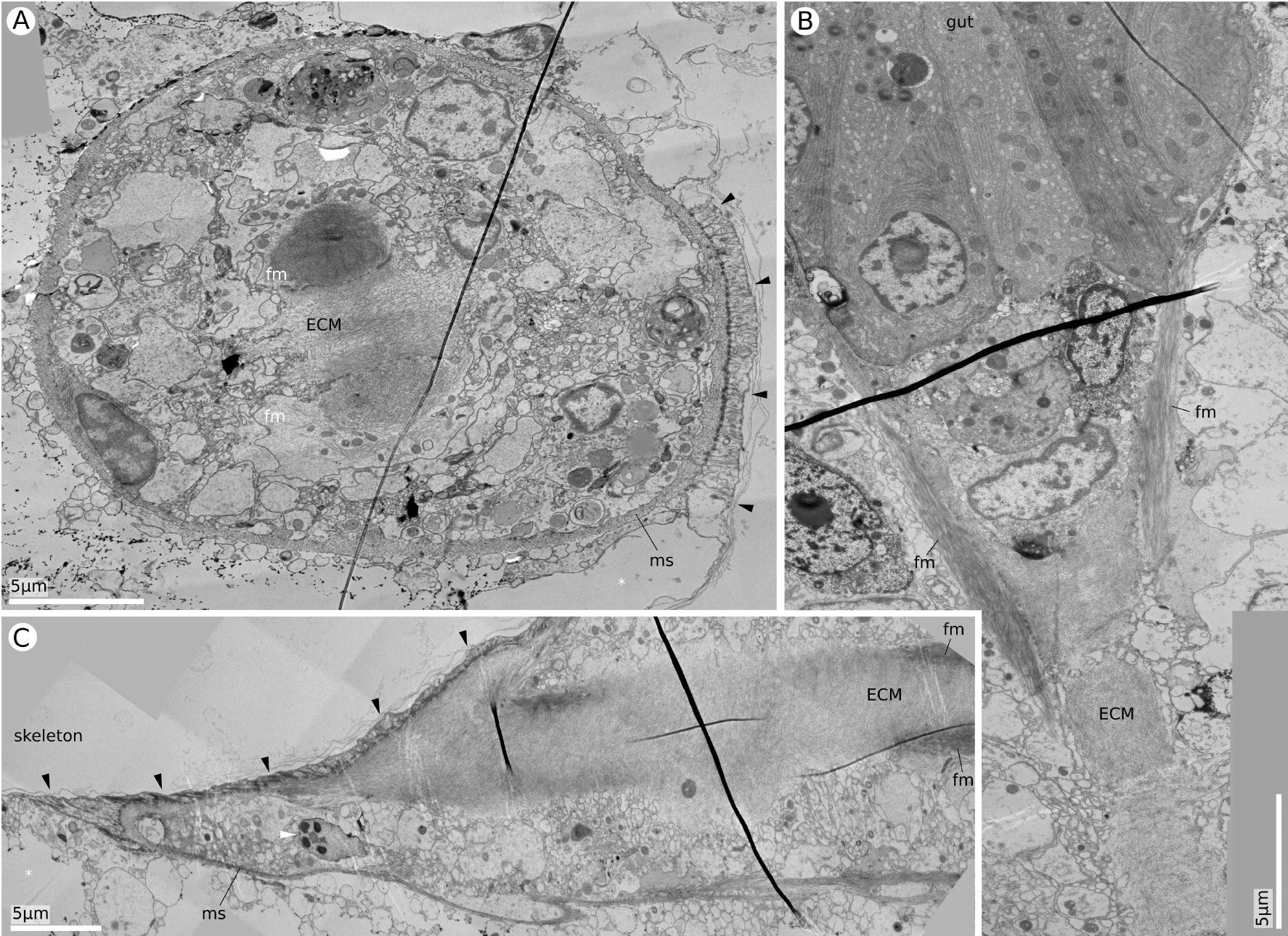

玹 